\title{
Comparison of Seismic and Geodetic Scalar Moment Rates across the Basin and Range Province
}

\author{
by Aasha Pancha, John G. Anderson, and Corné Kreemer
}

\begin{abstract}
Scalar moment rates estimated from a 146-year seismicity catalog agree, within uncertainties, with the deformation rate of the Basin and Range province determined by using space geodesy. Seismic-moment rates have been estimated from a new catalog of earthquakes complete for $M \geq 5$. The catalog was compiled from 15 preexisting catalogs, supplemented by the review of 44 journal articles. Throughout the catalog compilation, care was taken to obtain the moment magnitude or a reasonable, and not inflated, equivalent. Seventy-six percent of the moment release occurred during 10 earthquakes of magnitude $M_{\mathrm{W}} \geq 6.79$. The spatial distribution of earthquakes and their moment release matches the geodetic pattern of deformation. All three are concentrated in a $\sim 200-\mathrm{km}$-wide zone along the western boundary of the Great Basin, with this zone widening to the north. Several techniques, ultimately traceable to Kostrov and Brune, are used to translate the geodetic strain rates into rates of seismic-moment release. The agreement between geodetic and seismicmoment rate suggests that, within uncertainties, the rate of historic earthquakes within the Basin and Range province, taken as a whole, provides a reasonable estimate for the future rate of seismicity. These results support the hypothesis that even a few years of detailed geodetic monitoring can provide a good constraint on earthquake occurrence rate estimates for large-enough regions.
\end{abstract}

\section{Introduction}

Earthquake occurrence rates are an essential part of seismic-hazard analysis. There are now three major types of data available to estimate these occurrence rates: historical seismicity, geological slip rates on active faults, and geodetic deformation rates. Each approach has limitations, but in principle they should all yield similar estimates. In the following, we compare these three approaches in the Basin and Range region of the western United States.

Comparisons of seismicity and geology (e.g., Anderson, 1979; Doser and Smith, 1989) or comparisons of seismicity and geodesy (e.g., Ward, 1998a, 1998b; Shen Tu et al., 1998; Kreemer et al., 2000, 2002; Masson et al., 2005) have been conducted. This study improves on previous studies by including a decade of geodetic data, an improved seismicity catalog, and an attempt to characterize all of the active faults.

The adequacy of seismic catalogs to estimate average regional earthquake occurrence rates is governed by the catalog duration (Smith, 1976; Ward, 1998a) and the regional strain rate (Ward, 1998a). For seismicity rates estimated from the historical earthquake catalogs to be valid, the average recurrence interval is required to be shorter than the historical record. For an individual fault a complete earthquake cycle is required. Alternatively, for a region containing multiple faults, the historical seismicity record is re- quired to be long enough to capture a statistical sample of all phases of the seismic cycle, including of course earthquakes, but different parts of the cycle can be represented by different faults. With this constraint, the catalog duration is almost always too short to give a reliable occurrence rate estimate for regions the size of an urban area, as desired for seismic-hazard analysis.

Fault slip rates may be used to estimate average regional earthquake occurrence rates (e.g., Brune, 1968; Wallace, 1970; Anderson, 1979; Molnar, 1979, Doser and Smith, 1982). For such geological estimates of seismicity to be reliable, all major faults must be recognized and characterized correctly. Where faulting is concentrated on a few major through-going structures, as in coastal California north or south of the Transverse Ranges, there is reason for confidence that this goal is close to being achieved. In the Basin and Range, fault characterization is incomplete.

Two conditions for geodesy to give reliable estimates of earthquake occurrence rates are necessary. First, the geodetic measurements should sample a large enough spatial scale so that they are not affected by nonlinear strain accumulation during the earthquake cycle on individual faults. Second, they should sample a long enough time interval that measurement uncertainties have a minimal effect on the es- 
timated velocities. In the Great Basin, geodetic data meeting these conditions are obtained with as little as a few years of observations using the Global Positioning System (GPS), but the deformation is not uniquely assignable to specific faults. Agreement between the strike of active Quaternary faults and the azimuth of contemporary deformation lead Hammond and Thatcher (2004) to conclude that geodetic motion can be used to infer deformation over many earthquake cycles. Contemporary strain rates may be used to predict average earthquake moment rates using methods ultimately traceable to Kostrov (1974) or Brune (1968), assuming that all of the strain that is accumulated is ultimately released in earthquakes (e.g., Anderson, 1979; Ward, 1994; Working Group on California Earthquake Probabilities, 1995; Savage and Simpson, 1997; Shen-Tu et al., 1998; Ward, 1998a, 1998b).

The Basin and Range province extends from the rigid Sierra Nevada block in the west to the Colorado Plateau in the east (Fig. 1). The province is an actively deforming re- gion of Cenozoic extension and shear, dominated by normal faulting throughout with strike-slip deformation superimposed primarily along the western margin of the Great Basin (Stewart, 1988). High heat flow, negative Bouguer gravity anomalies, thin crust and lithosphere, and high-attenuation low-velocity upper mantle characterize the region (Catchings and Mooney, 1991; Jones et al., 1992; Chulick and Mooney, 2002; Zandt et al., 1995). From the geodynamic viewpoint, buoyancy forces within the crust and lithosphere (Wernicke, 1992; Sonder and Jones, 1999), tractions applied to the plate edge (Wernicke, 1992), and forces applied to the base of the lithosphere (Wernicke, 1992; Sonder and Jones, 1999) are all potentially contributing to drive the extension and shear observed in the region. Topographic and geodetic data, along with plate-motion constraints, indicate that extension is driven in part by gravitational potential energy, but plate-boundary interaction stresses modify extension directions (Flesch et al., 2000). In addition to spreading, about $25 \%$ of the Pacific-North American (PA-NA) relative plate

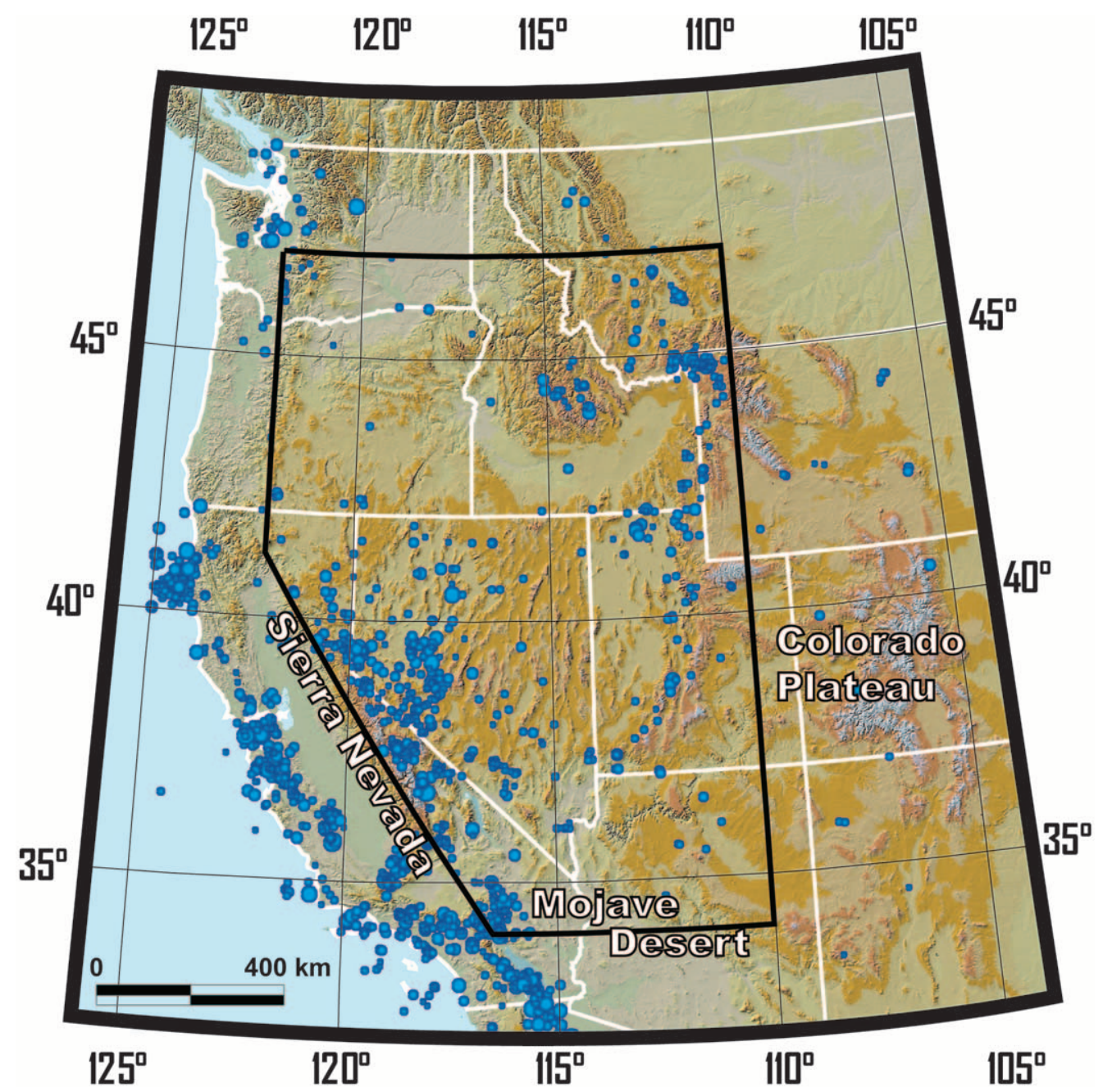

Figure 1. Map of the western United States, showing topography and earthquakes with $M \geq 4.8$ (blue circles with radius proportional to magnitude). The study area, outlined with a bold polygon, encloses all major earthquakes that can be associated with deformation of the Basin and Range province. 
motion $(\sim 12 \mathrm{~mm} / \mathrm{yr})$ is taken up by displacement and deformation in the Basin and Range province (Dokka and Travis, 1990; Dixon et al., 2000; Bennett et al., 2003).

Because deformation is distributed over a region nearly $1000 \mathrm{~km}$ wide, most major Basin and Range faults have recurrence times of several thousand years (Wallace, 1984; McCalpin and Nishenko, 1996; Lee et al., 2001; Dixon et al., 2003). We propose, however, that the deformation rate is fast enough that meaningful comparison of average seismicity rates estimated using seismic, geological, and geodetic data can still be accomplished for this region as a whole. The distributed seismicity of the region is assumed to be caused by a sufficient number of faults at different stages of the earthquake cycle to compensate for the long recurrence interval of the individual faults. This is reasonable because there are more than 400 major range-front faults distributed throughout the region (dePolo, 1998). Unfortunately many of the slip rates available for the region are based on reconnaissance techniques (dePolo, 1998) rather than on more detailed trenching. Geodetic strain measurements averaged over the region should be representative of the total geological strain across the entire region, considering that geodetic strain rates based on a decade of observations are broadly consistent with global plate models based on rates of seafloor spreading. Shen-Tu et al. (1998) and Humphreys and Weldon (1994) showed that fault slip rates in the western United States add up to be close to geological and geodetic estimates of the PA-NA motion. Although the geodesy data contain transients and localized areas of higher strain, these are small anomalies compared with the greater region.

To compare the three methods, we compile the best available GPS, geology, and seismicity data. GPS data from several studies in the Basin and Range area are combined for this study to model the present-day deformation field. Best estimates of slip rates on the most active faults characterized are obtained from input to the 1996 and 2002 U.S. Geological Survey (USGS) seismic hazard maps (Frankel et al., 1996, 2002; Haller et al., 2002).

To characterize the historical seismicity, this study compiles the most complete possible seismic-event catalog for the Basin and Range with strong emphasis on obtaining the most appropriate moment magnitude $\left(M_{\mathrm{W}}\right)$ for each event. We utilize geodetic data from multiple stations in the Basin and Range to define the geodetic deformation on a fine spatial scale (5-km grid). This is in contrast to previous studies for the Basin and Range that utilized only a small number of data for this region (Ward, 1998a; Shen Tu et al., 1998). Besides the comparison of the entire region, we also compare the spatial distribution of earthquakes and their moment release with crustal deformation rates.

\section{Earthquake Data}

In considering the Great Basin, we also include part of the Mojave Desert where deformation is more related to the northward motion of the Sierra Nevada Mountains than to the main motion of the San Andreas fault (Fig. 1). The southern extent of the area considered passes between the 1992 Landers earthquake and the 1992 Big Bear earthquake, such that the Big Bear event is excluded from our earthquake catalog. Although the Landers earthquake represents stress transfer out of the San Andreas system into the eastern Californian shear zone (ECSZ), the Big Bear earthquake event represents deformation in the Mojave Desert (Hauksson et al., 1993).

Seismic moment, $M_{0}$, of an earthquake is defined in terms of source parameters as the product of average shear modulus $\mu$ of the crustal rock around the earthquake, area $A^{e}$ of the fault ruptured in the earthquake, and $D$, the average slip during the earthquake (Brune, 1968), that is,

$$
M_{0}=\mu A^{e} D
$$

In the context of this article, moment rate is estimated over time intervals of decades or longer from the sum of the moments of all earthquakes divided by the interval. Seismic moment can therefore also be related to the rate of crustal deformation.

We estimated seismic-moment rates from a new catalog of earthquakes from 1850 to the end of 1999, intended to be complete for magnitude $M \geq 5$ (Fig. 1). Earthquakes within the study region with $M \geq 4.8$ in any of 15 preexisting catalogs were selected (Table 1). After removing duplicate entries, the catalog contained a total of 800 earthquakes since 1855 , including 487 earthquakes with $M \geq 5.0$ (www.seismo.unr.edu/htdocs/BandR.html). By allowing a lower cutoff level of $M 4.8$, we sought to ensure that magnitude differences arising from the use of different catalogs is accounted for. In this way, no significant events should have been neglected from the catalog.

This new catalog was supplemented by the review of 44 published journal articles to obtain $M_{\mathrm{W}}$ values for many of the more prominent earthquakes (Slemmons, 1957; Tsai and Aki, 1966; Savage and Hastie, 1966, 1969; Bolt and Miller, 1975; Hanks et al., 1975; Hart et al., 1977; Langston and Butler, 1976; Hanks and Kanamori, 1978; Toppozada et al., 1981; Doser and Smith, 1982; Barrientos et al., 1985; Boatwright and Choy, 1985; Doser, 1985; Doser and Smith, 1985; Ekstrom and Dziewonski, 1985; Nabelek et al., 1985; Patton, 1985; Stein and Barrientos, 1985; Barker and Wallace, 1986; Doser, 1986; Sipkin, 1986; Ward and Barreintos, 1986; Doser, 1987; Doser and Kanamori, 1987; Barker and Doser, 1988; Doser, 1988; Pacheco and Nábĕlek, 1988; Patton and Doser, 1988; Doser, 1989a, 1989b; Doser and Smith, 1989; Westaway and Smith, 1989; Rogers et al., 1991; Smith and Arabasz, 1991; Kanamori et al., 1992; Beanland and Clark, 1993; Wells and Coppersmith, 1994; Caskey et al., 1996; Mason, 1996; dePolo and dePolo, 1999; dePolo et al., 2003; Ji et al., 2002; Ichinose et al., 2003). Only best estimates of the moment magnitude were considered from the literature. Some of the larger events consisted of a num- 
Table 1

Catalogs Included in the Compiled Earthquake Database

\begin{tabular}{|c|c|c|}
\hline Catalogs Searched & Abbreviation & Web Address \\
\hline Historical and preliminary data & PDE & www.neic.cr.usgs.gov/neis/epic/epic.html \\
\hline Significant earthquakes worldwide & NOAA & www.neic.cr.usgs.gov/neis/epic/epic.html \\
\hline Significant U.S. earthquakes & USHIS & www.neic.cr.usgs.gov/neis/epic/epic.html \\
\hline California & CDMG & www.neic.cr.usgs.gov/neis/epic/epic.html \\
\hline Canada & $\mathrm{EPB}$ & www.neic.cr.usgs.gov/neis/epic/epic.html \\
\hline Mexico, Central America, Caribbean & NGDC & www.neic.cr.usgs.gov/neis/epic/epic.html \\
\hline Eastern, Central and Mountain States & SRA & www.neic.cr.usgs.gov/neis/epic/epic.html \\
\hline Nevada Seismological Laboratory, University of Nevada, Reno & UNR 1852 & www.seismo.unr.edu/Catalog/catalog-search.html \\
\hline University of California, Berkeley & $\mathrm{BK}$ & www.ncedc.org/ncedc/catalog-search.html \\
\hline Council of the National Seismic System & CNSS & www.ncedc.org/cnss/catalog-search.html \\
\hline Pasadena & SCSN & www.data.scec.org/catalog_search/date_mag_loc.php \\
\hline Northern California Earthquake Data Center & NCSN & www.ncedc.org/ncedc/catalog-search.html \\
\hline Utah (regional and historic) & & www.quake.utah.edu/catalog/catalog.shtml \\
\hline Yellowstone & & www.quake.utah.edu/catalog/ynp.shtml \\
\hline Harvard & & www.seismology.harvard.edu/CMTsearch.html \\
\hline
\end{tabular}

ber of subevents. In these cases, the moments of each of the individual subevents were summed and the moment magnitude was calculated from that total.

The initial compiled catalog contained multiple entries from the same earthquake. Discrepancies were noted between catalog listings for single events. Timing differences of up to one day were observed, as well as differences in location, especially for early events. Some events were not listed in their primary catalogs. Hence, a small amount of subjectivity, based on the similarities of both the location and timing of events, was introduced for event association between catalogs. Errors were often noted in secondary sources. Where available, primary sources were therefore preferred.

Emphasis was placed on the accuracy of the magnitudes within each catalog listing, as discussed in the next section. The main objective was to include all the large earthquakes within the region and gain a reasonable estimate of $M_{\mathrm{W}}$ or a reasonable equivalent. Preferred locations were those from primary catalogs, except where geological data have been used in relocations. In general, less emphasis was placed on the accuracy of the timing of events.

Large uncertainties surround some large historic events. Several catalogs include an earthquake in 1852 in western Nevada with $M$ 7.3. The anecdotal evidence for this earthquake is not sufficient to assign a magnitude and location that is reliable enough to use in this study. The occurrence of the 1903 M 6.5 earthquake (Slemmons et al., 1959; Rogers et al., 1991) is based on geological mapping, field studies, and interviews with residents. Although omitted by many other catalogs, we include this event in our final catalog as its occurrence is sufficiently credible. Because of its smaller size, it does not contribute greatly to the final cumulative seismic-moment release of the region.

Earthquakes that are potentially related to volcanic processes, including those associated with activity around
Mammoth Lakes and Mt. St. Helens, were included in the catalog. The Mt. St. Helens events were of magnitude M 5.3 or less and, hence, contribute little to the overall seismicmoment release. The largest events near Mammoth Lakes $(M \sim 6)$ occur outside the caldera, so that they may appropriately be considered to contribute to the tectonic deformation of the region. Events in the locality of the Nevada Test Site, occurring at times of known nuclear blasts, were removed from the final database. Three additional events were removed, as they were located on the Nevada Test Site and occurred either exactly on the hour or half hour. All other events in the vicinity are assumed to be of tectonic origin or triggered by the blasts.

Amplitude spectra of surface waves were used by Patton (1985) to determine seismic moments of western United States events with $M_{\mathrm{L}}$ and $m_{\mathrm{b}}$ between 4.3 and 5.5. Whereas magnitude estimates from other sources were $M \geq 4.8$, the moment magnitudes estimated by Patton (1985) were often less than this. This discrepancy arises because of the highfrequency content of these smaller events. Based on the rules for magnitude selection below, these smaller moment magnitudes are used in the analyses.

Doser and Smith (1982) found that some events with $M_{\mathrm{L}}<4.8$ can be modeled to give an estimate of $M_{\mathrm{W}}>4.8$; these events are included in the new catalog. Thus, we may not have achieved completeness in the $M_{\mathrm{W}}$ 4.8-5.5 range. However, these events would not have an impact on the main results of this study because of their small size.

Geological parameters given by Wells and Coppersmith (1994) and Mason (1996) were used to calculate momentrelease values for significant earthquake events from equation (1) using a shear modulus of $\mu=3 \times 10^{11}$ dyne $\mathrm{cm}^{2}$. To determine $A^{e}$ for normal faults, the dip was assumed to be $60^{\circ}$, whereas for strike-slip events, the dip was assumed to be $90^{\circ}$. Mason (1996) did not give estimates of the vertical depth of the faulting. Those given by Wells and Coppersmith 
(1994) were therefore used in calculation of the seismic moment from source parameters listed by Mason (1996). Best estimates of the fault length and displacement, as given by Mason, were used. In the case of the Wells and Coppersmith (1994) data, the surface fault length and average displacement were used. For four small earthquakes where average displacements were not available, maximum displacements were used. Equation (1) was also applied to other earthquake source parameter data listed within the literature.

These calculated moment values and those within the literature were converted to moment magnitude estimates, so that they could be compared with other magnitude estimates for each respective event using the relation first defined by Kanamori (1977):

$$
M_{\mathrm{W}}=\frac{2}{3} \log _{10} M_{0}-10.73
$$

\section{Magnitude Assignment}

For most earthquakes, we estimated the seismic moment $M_{0}$ from magnitude $M_{\mathrm{W}}$, so careful attention was paid to the magnitudes of each event in the catalog, as small biases in magnitudes can result in a large bias in the strain rate (Wang et al., 1982). Moment magnitude estimates were selected when available. For the largest events, for which many $M_{\mathrm{W}}$ estimates are available, we established criteria to select the favored $M_{\mathrm{W}}$ value. The selection criteria are described below. For events without $M_{\mathrm{W}}$ estimates, care was taken to avoid inflated magnitude estimates, usually by using the smallest magnitude from any catalog. This yields a lowerbound estimate for the occurrence rate of moderate earthquakes. Exceptions were made in cases where the primary catalog source was preferred. In addition, $M_{\mathrm{S}}$ estimates were preferred over $m_{\mathrm{b}}$ because they are more representative of $M_{\mathrm{W}}$ for large-magnitude events (Kanamori, 1983).

Careful selection criteria were established to retain the best $M_{\mathrm{W}}$ estimate from the literature and catalog listings for the largest events. The Harvard long-period surface-wave estimates of the seismic moment have been consistent for the past 28 years; hence, these estimates were given primary preference. Second preference was given to other surfacewave moment tensor estimates followed by any other surface-wave estimates. Long-period surface waves are considered to be more representative of the average faulting process than body waves and thus were given precedence over moment estimates based on body waves. Within each of these $M_{\mathrm{W}}$ categories, the catalog record with the minimum-magnitude listing was retained. After surface waves, body wave and/or $P n l$ wave, geological, and leveling data were then considered in the same category. In these cases, we needed to use judgment based on the quality of the data; because of concerns that each of these have the potential to underestimate the size of the earthquakes, we tended to favor larger values. Appendix 1 describes in detail how preferred
$M_{\mathrm{W}}$ values were selected for each of the 10 largest earthquake events in the catalog, and are listed in Table 2.

All magnitudes within the catalog were then treated as moment magnitudes. We then estimated the seismic moment of each event using the relation

$$
M_{0}=10^{3 / 2 M_{\mathrm{w}}+16.095}
$$

from inverting equation (2) exactly. Different values of the constant, instead of 16.095, are in the literature, as discussed by Anderson (2003) and Utsu (2003). These differences are a result of rounding of the coefficients. Equation (2) is based on the original definition rounded to two decimal places. We have chosen to use equation (2) because the Harvard Centroid Moment Tensor (CMT) Catalog uses it in their determination of seismic moment for large earthquakes and these have been consistent for the last 28 years. Although we have been consistent in the use of equation (2), we note that within some of the literature and in several catalog listings that a constant coefficient of 10.7 had been applied.

Figure 2 shows $M_{\mathrm{W}}$ and coda magnitude estimates for 113 moderate-magnitude earthquakes from 1990 to 2000 in the western Great Basin. Moments are determined by Ichinose et al. (2003). Although these smaller events have relatively little influence on the study results, we use these results as an indication that our use of network magnitude estimates in the place of $M_{\mathrm{W}}$ does not cause major bias.

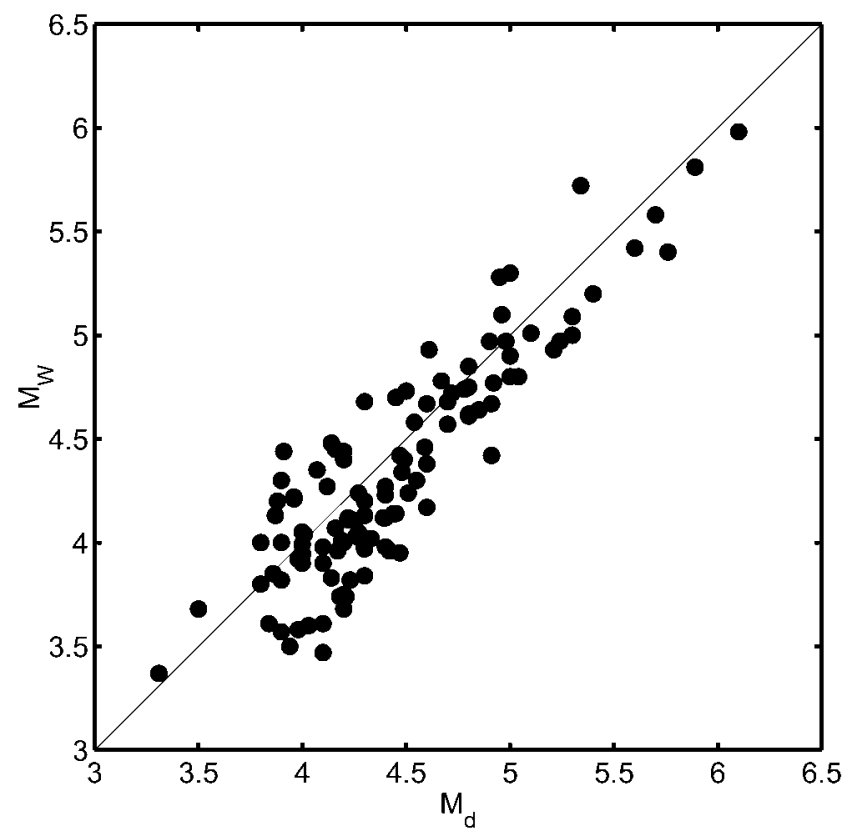

Figure 2. Coda magnitude $M_{\mathrm{d}}$ versus moment magnitude $M_{\mathrm{w}}$ for 113 earthquakes from 1990 to 2000 located within the western Great Basin. Moments were determined by Ichinose (2003). On average, $M_{\mathrm{d}}-M_{\mathrm{w}}=0.10 \pm 0.25$. 
Table 2

Ten Largest Events in the Compiled Catalog

\begin{tabular}{|c|c|c|c|c|c|c|c|c|c|c|}
\hline \multirow[b]{2}{*}{ Year } & \multirow[b]{2}{*}{ Month } & \multirow[b]{2}{*}{ Day } & \multirow[b]{2}{*}{ Hour } & \multirow[b]{2}{*}{ Minute } & \multirow[b]{2}{*}{ Latitude } & \multirow[b]{2}{*}{ Longitude } & \multicolumn{3}{|c|}{ Magnitude $M_{\mathrm{W}}$} & \multirow[b]{2}{*}{ Earthquake Name } \\
\hline & & & & & & & Preferred & Minimum & Maximum & \\
\hline $1872 *$ & 3 & 26 & 10 & 30 & 36.70 & -118.10 & 7.58 & 7.44 & 7.70 & Owens Valley \\
\hline $1915^{\dagger}$ & 10 & 3 & 6 & 53 & 40.50 & -117.50 & 7.15 & 6.87 & 7.15 & Pleasant Valley \\
\hline $1932^{\ddagger}$ & 12 & 21 & 6 & 10 & 38.80 & -117.98 & 7.10 & 6.73 & 7.10 & Cedar Mountain \\
\hline $1954^{\S}$ & 8 & 24 & 5 & 51 & 39.60 & -118.50 & 6.76 & 6.16 & 6.77 & Stillwater \\
\hline $1954^{\|}$ & 12 & 16 & 11 & 7 & 39.20 & -118.00 & 7.12 & 6.95 & 7.36 & Fairview Peak \\
\hline $1954^{\#}$ & 12 & 16 & 11 & 11 & 39.67 & -117.90 & 7.06 & 6.53 & 7.24 & Dixie Valley \\
\hline $1959 * *$ & 8 & 18 & 6 & 37 & 44.88 & -111.10 & 7.32 & 7.25 & 7.42 & Hebgen Lake \\
\hline $1983^{\dagger \dagger}$ & 10 & 28 & 14 & 6 & 44.96 & -113.90 & 6.93 & 6.82 & 7.25 & Borah Peak \\
\hline $1992^{\ddagger \neq}$ & 6 & 28 & 11 & 57 & 34.20 & -116.44 & 7.29 & 7.19 & 7.30 & Landers \\
\hline $1999^{\S \S}$ & 10 & 16 & 9 & 46 & 34.59 & -116.27 & 7.12 & 7.10 & 7.14 & Hector Mine \\
\hline
\end{tabular}

*The preferred magnitude is from Wells and Coppersmith (1994), whereas the minimum and maximum estimates are from Beanland and Clark (1993).

†The preferred and maximum magnitude is from Wells and Coppersmith (1994), the minimum is from Doser and Smith (1989).

*The preferred and maximum magnitude is from Wells and Coppersmith (1994), the minimum is from Doser and Smith (1989).

${ }^{\S}$ The preferred and maximum magnitude is from Mason (1996), the minimum is from Barker and Doser (1988).

"The preferred and maximum magnitude is from Doser and Smith (1989) and the minimum is from Mason (1996).

${ }^{\#}$ The preferred and minimum magnitudes are from Doser and Smith (1989), whereas the maximum is from Caskey et al. (1996).

**The preferred magnitude is from Doser and Smith (1989), the maximum is from Savage and Hastie (1969), and the minimum is from Doser (1985) and Doser and Smith (1989).

${ }^{\dagger}$ The preferred magnitude is from Harvard, the maximum and minimum are from Mason (1996) and Doser and Smith (1989), respectively.

${ }^{*}$ The preferred magnitude is from Harvard and the maximum and minimum are from Kanamori et al. (1992) and Wells and Coppersmith (1994), respectively.

${ }^{\S \S}$ The preferred magnitude is from Harvard, the maximum estimate is from Ji et al. (2002), and the minimum is from University of California, Berkeley, and the Council of the National Seismic System catalogs.

\section{Strain Rate Field Model from GPS Velocities}

Geodetic measurements show concentrated deformation at the eastern $(\sim 50 \mathrm{~km})$ and western $(\sim 200 \mathrm{~km})$ margins of the Basin and Range, coinciding with regions of modern seismicity, and with little deformation in between (Dixon $e t$ al., 1995; Thatcher et al., 1999; Dixon et al., 2000; Svarc et al., 2002b; Bennett et al., 2003; Hammond and Thatcher, 2004). Concentration of deformation in the westernmost $200 \mathrm{~km}$ of the Basin and Range and along the eastern boundary may be related to rheological weakness of the lithosphere (Thatcher, 2003). Margin parallel velocities at a latitude of $39-40^{\circ} \mathrm{N}$ increase from $\sim 1$ to $2 \mathrm{~mm} / \mathrm{yr}$ at $117.7^{\circ} \mathrm{W}$, representative of the relatively more stable interior of the Basin and Range, to $\sim 12 \mathrm{~mm} / \mathrm{yr}$ at $120^{\circ} \mathrm{W}$ (Bennett et al., 2003; Hammond and Thatcher, 2004). Strain rates also increase from north to south along the western boundary of the region (Bennett et al., 2003) because of narrowing of the highdeformation zone from the northern Walker Lane to the ECSZ in the south.

For the purpose of this study it is appropriate to model the present-day deformation field by means of a continuous strain rate field based on GPS velocity observations. For this, we apply a spline interpolation technique (Haines and Holt, 1993; Holt et al., 2000) in which model velocities are fitted to observed GPS velocities in a least-squares sense, using the full data covariance matrix. After a continuous velocity gradient tensor field model has been obtained, we calculated model velocities for $0.05^{\circ}(5 \mathrm{~km})$ grid intervals to do the analysis in sections: Spatial Distribution of Moment and Geodetic Moment Rates.

We combine GPS velocities from multiple studies in the Great Basin area. Some of these studies are published (Freymueller et al., 1999; McClusky et al., 2001; Oldow et al., 2001; Svarc et al., 2002a, 2002b; Mazzotti et al., 2003; Hammond and Thatcher, 2004; Savage et al., 2004), others have been made available otherwise: Eastern Basin-Range and Yellowstone Hotspot GPS Network (EBRY) (R. Smith, personal comm., 2003); Southern California Earthquake Center (SCEC) Crustal Motion Map v.3; Basin and Range Geodetic Network (BARGEN) (R. Bennett, personal comm., 2003). In addition we have used several unpublished USGS GPS results from campaign-style surveys: these consist of the Hawthorne Profile, (part of) the Mammoth network, and networks presented by Hammond and Thatcher (2003) and Hammond et al. (2004).

Each of the geodetic studies used has realized a unique frame of reference (in general, by assuming North America [NA] to be stable). To be consistent, we have applied Helmert transformations (when possible) to translate velocities into the global GPSVEL velocity solution (Lavallée et al., 2001) which is in the ITRF2000 frame. We subsequently rotate all velocities into a North America fixed reference frame, using the ITRF2000 pole obtained from the GPSVEL solution: $3.0^{\circ} \mathrm{S}, 83.1^{\circ} \mathrm{W}, 0.198^{\circ} / \mathrm{Ma}$. For some studies we have multiplied standard errors in the velocity components 
with a factor: EBRY data times 10, BARGEN data times 10, (Savage et al., 2004) times 2, (McClusky et al., 2001) times 2, and (Oldow et al., 2001) times 20.

\section{Analysis and Results}

\section{The Completeness of the Earthquake Catalog}

Figure 1 shows the epicenters of all earthquakes in the catalog developed in the preceding section. Earthquakes are concentrated along the southwestern and eastern boundary of the region. The catalog is more complete in recent years. Completeness as a function of magnitude was determined from average rate plots, following the method of Stepp (1972) (Fig. 3). The average rate in magnitude intervals was determined from the most recent $y$ years of data. Considering this average as a function of $y$, the point at which the function begins to decline indicates the duration of completeness. From Figure 3 we estimate that earthquakes of $M \geq 4.8$ are complete since $1954, M \geq 5.5$ earthquakes are complete since $1932, M \geq 6.0$ earthquakes are complete since 1901 , and $M \geq 7.0$ earthquakes are complete for the entire duration of the catalog back to 1855 .

Considering completeness intervals for various magnitudes, the discrete Gutenberg-Richter relation for the number of earthquakes, $n$, equal to magnitude $M \pm 0.25$ is $\log n=$ $5.66-1.00 M$ (Fig. 4a). Using cumulative rates of occurrence over appropriate catalog durations, we obtain a relation of $\log N=6.66-1.15 M$ (Fig. 4b), yielding 4.4 earthquakes per century with $M_{\mathrm{W}} \geq 7.0,0.54$ earthquakes per year with $M_{\mathrm{W}} \geq 6.0$, and 6.6 earthquakes per year with
$M_{\mathrm{W}} \geq 5.0$. These $b$-value curves are sensitive to the magnitudes assigned to each earthquake. Of the total moment, $76 \%$ was released during 10 earthquakes of magnitude $M_{\mathrm{W}} \geq 6.79$ (Table 2), and $90 \%$ was released in the 38 events of $M_{\mathrm{W}} \geq 6.1$. This confirms the observation that small events do not significantly release accumulating strain (Brune, 1968; Anderson, 1979; Anderson and Luco, 1983; Shen-Tu et al., 1998).

\section{Spatial Distribution of Moment}

Figure 5 shows the boundaries of four domains (A-D) that we use to compare deformation and seismicity. The four domains are each $300 \mathrm{~km}$ wide. Figure 6 shows the magnitude of crustal velocity, as determined from inversion of the geodetic model, along profiles. These velocities give a smoother picture of the deformation field than the calculated strain-rate field. A northward broadening of the zone of high deformations is evident, as observed by Bennett et al. (2003).

Figure $7 \mathrm{a}-\mathrm{d}$ compares these deformation profiles with the spatial distribution of earthquake numbers and of moment release within each domain. The seismic moment of each earthquake is more completely represented as a tensor. Here we use the magnitude of the maximum eigenvalue. Although tensor information is available for the 10 largest earthquakes, which release $76 \%$ of the total seismic moment, use of tensors increases the number of degrees of freedom. Therefore a much longer observation time is required to obtain a reliable comparison with regional components of the geodetic strain, considering that there is randomness in fault orientations. (a)

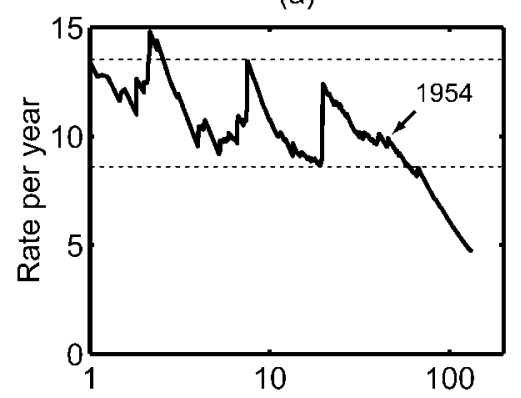

(c)

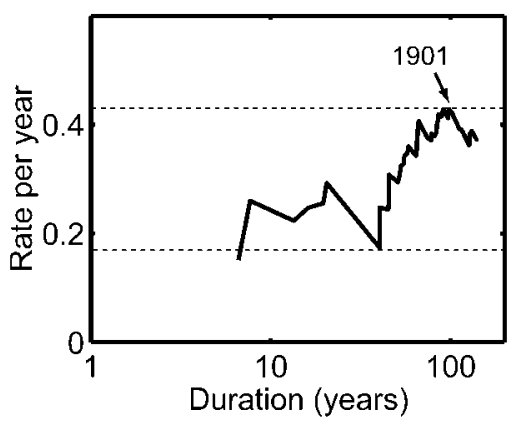

(b)

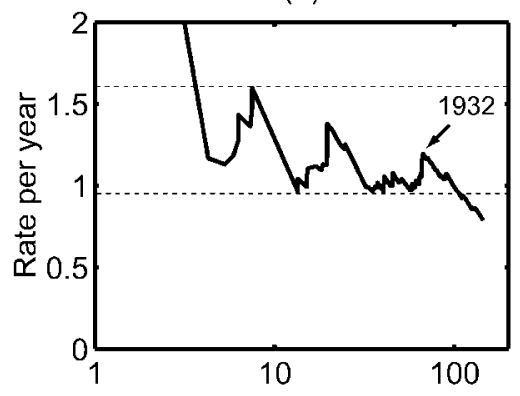

(d)

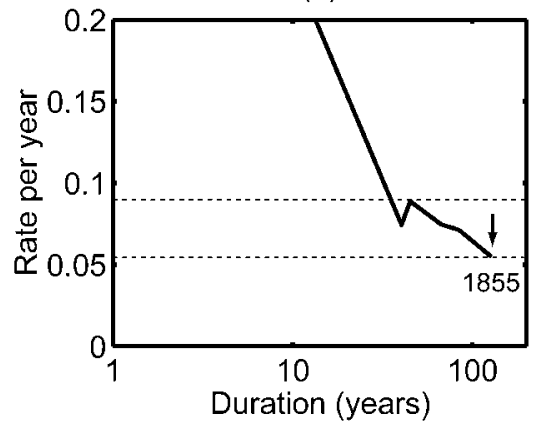

Figure 3. Average rate of earthquakes in four magnitude ranges, as a function of catalog duration, where a $y$-year average is based on the most recent $y$ years of the catalog ending 31 December 1999. Magnitude ranges are: (a) $4.8 \leq M \leq 5.4$; (b) $5.5 \leq M \leq 5.9$; (c) $6.0 \leq$ $M \leq 6.9$; (d) $M \geq 7.0$. The duration of catalog completeness is estimated from the point at which the rate of earthquakes falls off (shown by arrows). Horizontal dotted lines indicate the upper and lower range of the earthquake rates. Completeness durations determined from these figures are applied to smaller magnitude intervals to generate the occurrence rates shown in Figure 4. 
(a) Rates in magnitude intervals

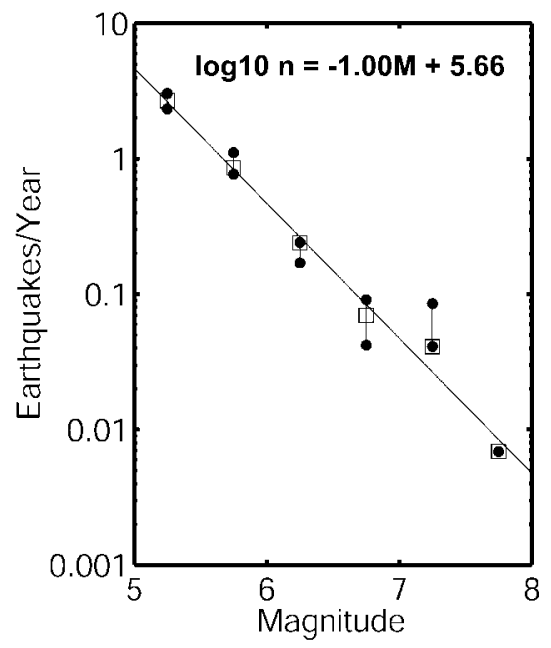

(b) Rates for exceeding magnitude $M$

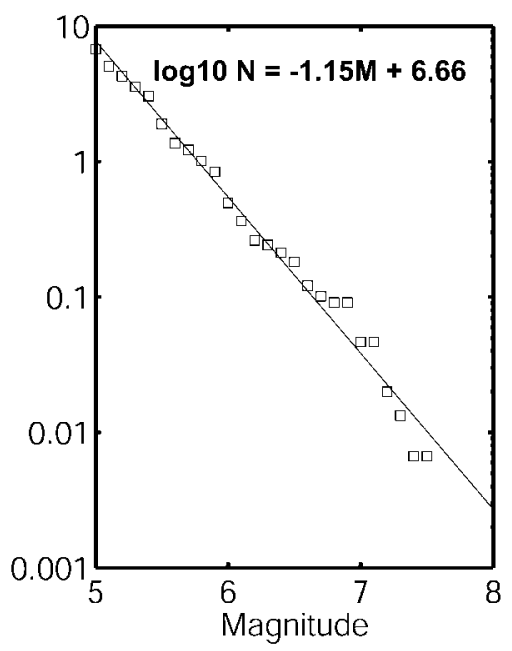

Figure 4. $\quad b$-value curves for the study region. (a) Discrete occurrence rates, where $n$ is the discrete number of earthquakes in the magnitude range $M \pm 0.25$. Error bars show the uncertainty range determined using the method illustrated in Figure 3. A different estimate for the uncertainty in the number of events per year can be inferred from the plot because earthquake occurrences are approximately a Poisson process (the approximation is better for $M>6$ ), and for a Poisson process the variance is equal to the mean. (b) Cumulative earthquake occurrence rates, where $N$ is the total number of earthquake events of magnitude $M$ or greater.

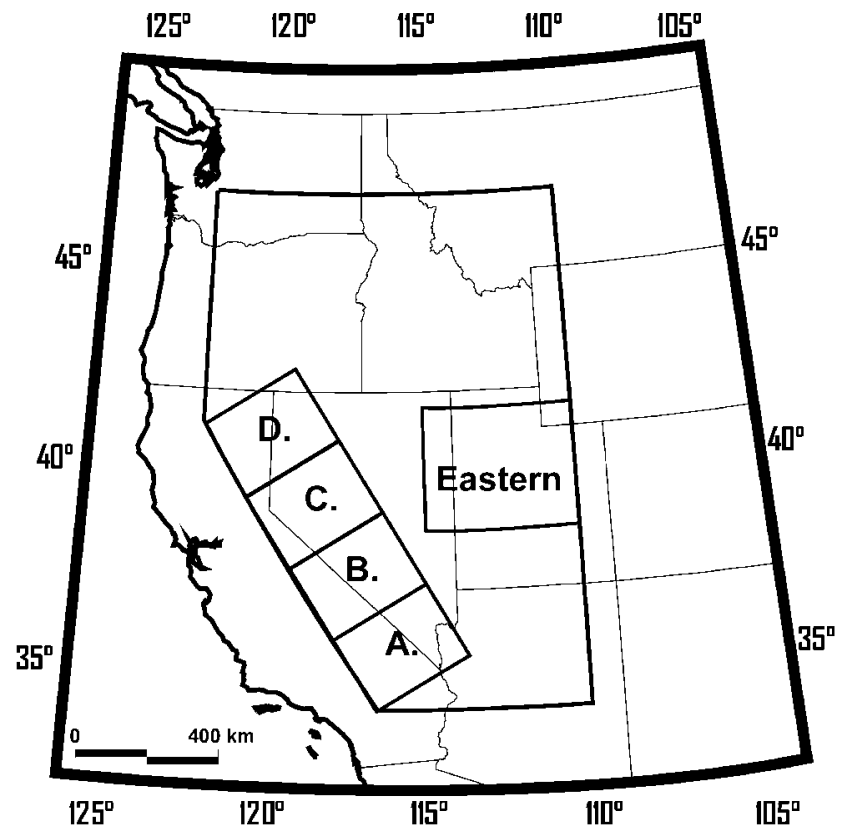

Figure 5. Map of study showing the location of regional domains through which the profiles shown in Figures 6, 7, and 8 are taken.

The spatial patterns of seismic activity, seismic moment release, and geodetic deformation are similar along all of the profiles and show a northward widening of the deformation zone along the western edge of the province. One way to quantify the similarity of the profiles in Figure 7 is to tabulate the distances from the southwest boundary to the point along the profile within which $75 \%$ of the total of each activity measure occurs (Table 3 ). For profiles A, C, and D these widths agree within 20\%. Across domain B (Fig. 7b), $75 \%$ of the earthquake numbers and the geodetic deformation occur within a zone about $90-113 \mathrm{~km}$ wide, but the moment release is concentrated by the 1872 Owens Valley event (Table 2), the largest event in the catalog. Removal of the $1872 M_{\mathrm{W}} 7.58$ event results in improved correspondence between the three curves (Fig. 7b; Table 3). The 1915 Pleasant Valley (domain D) and 1872 Owens Valley (domain B) events occurred prior to when seismic instrumentation was capable of observing aftershocks. If those aftershocks could be included the distribution of earthquake numbers would change.

Plots similar to those in Figure 7 for the eastern domain (Fig. 5) are shown in Figure 8. Scales along the ordinate axes are normalized by the largest values in the study region for this latitude range. This allows comparison with profiles in Figure 7. The figure shows that activity along the eastern half of the Great Basin, across the Wasatch Mountains (Fig. 5), is significantly smaller than in the west. The greatest increase on all three rates in Figure 8 occurs near the Wasatch Front at $112^{\circ} \mathrm{W}$. About $13 \%$ of the earthquakes and $4 \%$ of the seismic moment are concentrated east of $112.2^{\circ} \mathrm{W}$. Less than about $15 \%$ of the geodetic deformation occurs there. Malservisi et al. (2003), in a study of similar GPS data, find that it is not possible to distinguish between two models: one being elastic strain accommodation on multiple faults with generally low strain rates (except the Wasatch) and the other being postseismic creep on the Wasatch fault.

Figures 7 and 8 suggest that spatial distribution of moderate $(M \sim 5)$ earthquakes and moment release are correlated in this region. If true, this implies that earthquake numbers and moment release could be used to constrain the geodetic deformation field and, conversely, be predicted from geodetic strain rates. Kreemer et al. (2002) have suggested that this is true on a global scale, whereas Masson et al. (2005) find this relation does not hold at a regional scale for Iran.

\section{Seismic Scalar Moment Rate}

The statistical procedure used to estimate the historical seismic-moment rate is illustrated in Figure 9, showing cumulative seismic moment as a function of time. As lower- 


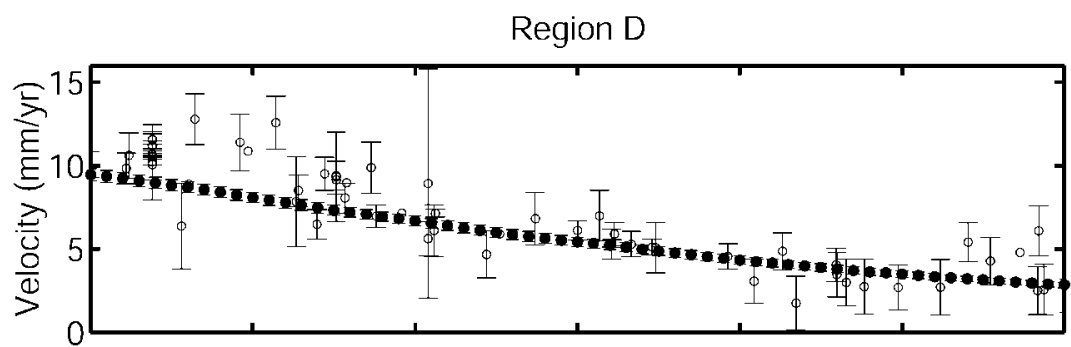

Region C

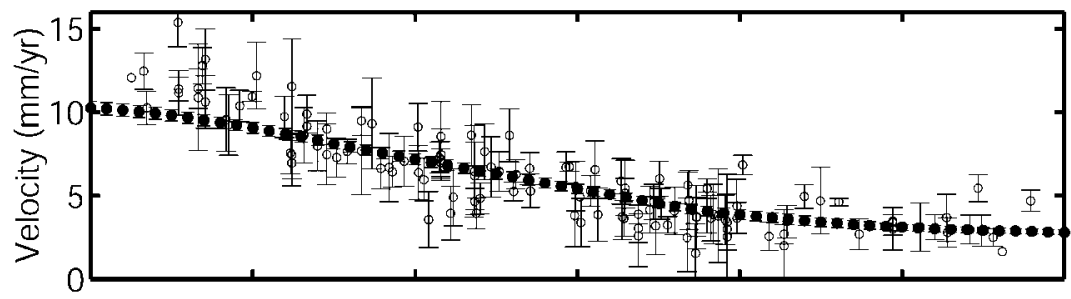

Region B

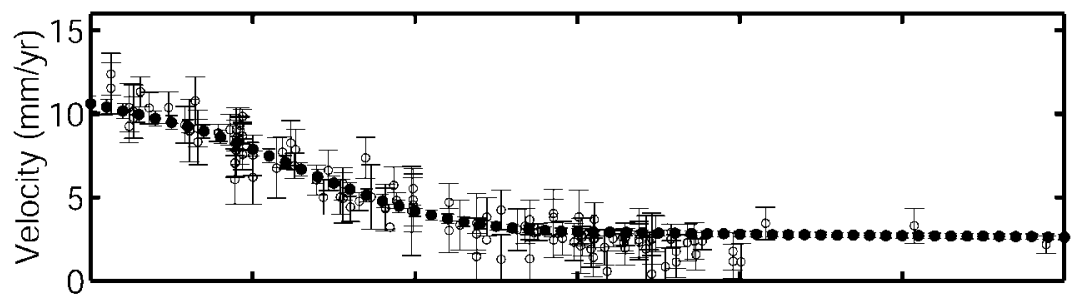

Region A

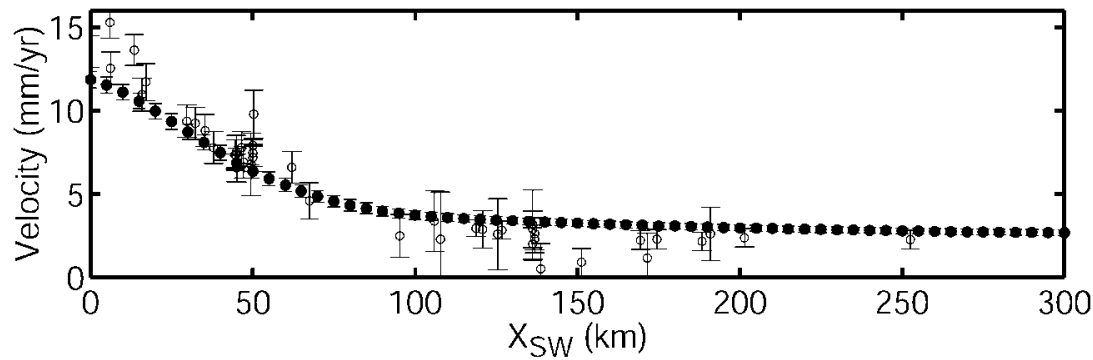

Figure 6. The magnitude of the velocity field determined from inversion of geodetic data (see text) as a function of $X_{\mathrm{SW}}$, the perpendicular distance from the southwestern boundary of the study region. The profiles are located along the upper half of domain $\mathrm{A}$ and the centers of domains B, C, and D (Fig. 5). Modeled velocities are shown (solid circles) along with one-standard-deviation error bars. GPS data used to derive the model are also shown (open circles) as well as their onestandard-deviation uncertainty limits.

Table 3

Estimated Widths of the Most Active Zones*

\begin{tabular}{|c|c|c|c|c|c|}
\hline \multirow[b]{2}{*}{ Domain } & \multirow[b]{2}{*}{ Figure } & \multicolumn{3}{|c|}{ Distance $(\mathrm{km})$ from Southwest Boundary } & \multirow{2}{*}{$\begin{array}{c}\text { Mean Width }(\mathrm{km}) \\
\text { Standard Deviation } \\
(\mathrm{km} \text { and as percent of mean })\end{array}$} \\
\hline & & $\begin{array}{l}\text { Earthquake } \\
\text { Number }\end{array}$ & Velocity & Moment & \\
\hline A & $7 \mathrm{a}$ & 52 & 71 & 52 & $58 \pm 11(19 \%)$ \\
\hline B & $7 \mathrm{~b}$ & 113 & 90 & 30 & $77 \pm 43(56 \%)$ \\
\hline B, without 1872 & $7 \mathrm{~b}$ & 113 & 90 & 55 & $86 \pm 29(34 \%)$ \\
\hline $\mathrm{C}$ & $7 \mathrm{c}$ & 159 & 171 & 204 & $178 \pm 23(13 \%)$ \\
\hline $\mathrm{D}$ & $7 \mathrm{~d}$ & 164 & 186 & 164 & $171 \pm 13(8 \%)$ \\
\hline
\end{tabular}

*Width measured from the south-west boundary to a distance enclosing $75 \%$ of the number of earthquakes, velocity as measured by GPs, or total seismic moment within each domain (see Figure 7a-d).

bound magnitudes of moderate earthquakes were considered, this yields lower-bound estimates of the moment release rate. A least-squares fit to the points in Figure 9 (1 point for each year with an earthquake) has a slope of $6.85 \times 10^{25}$ dyne $\mathrm{cm} / \mathrm{yr}$. Lines on Figure 9 show a non- unique, but plausible rationale for moment rates as low as $6.15 \times 10^{25}$, or as high as $8.84 \times 10^{25}$ dyne $\mathrm{cm} / \mathrm{yr}$.

To quantify uncertainties associated with these seismicmoment rates, we repeated the procedure shown in Figure 9; (1) using upper-bound estimates of the magnitudes of the 
(a)
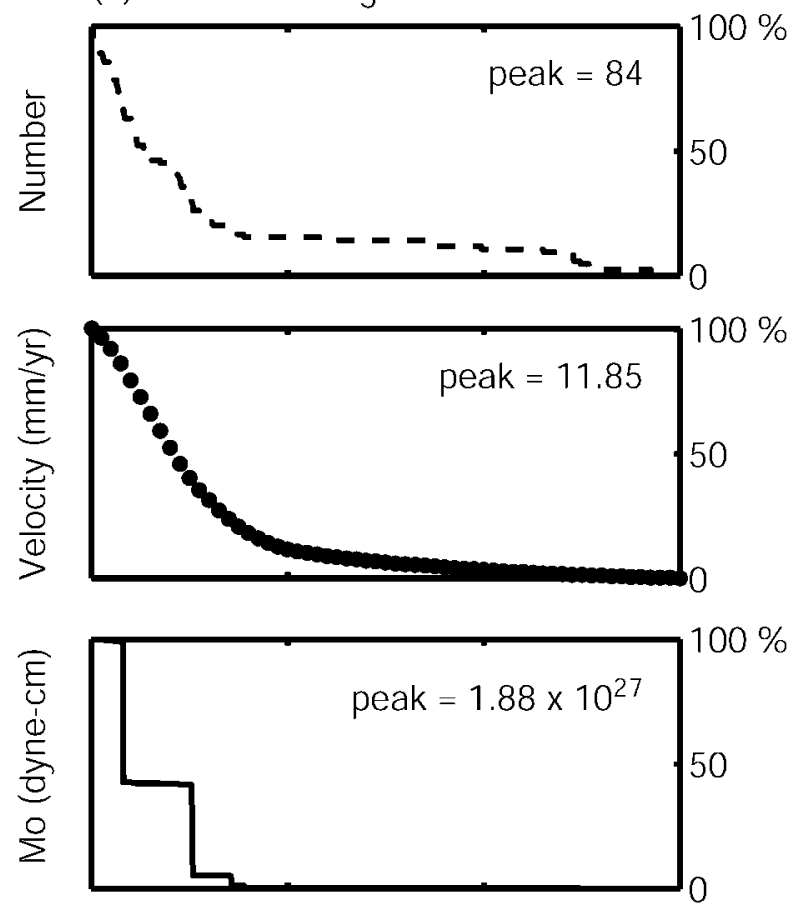

(c)

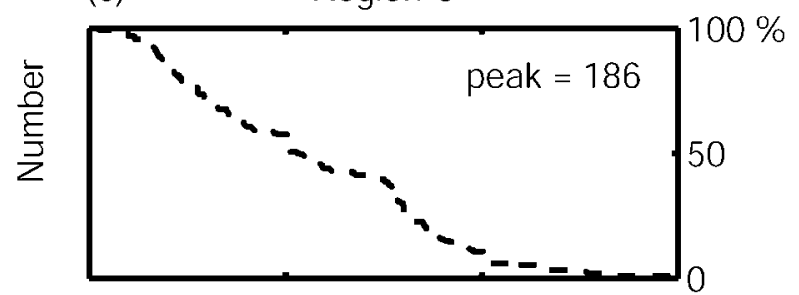

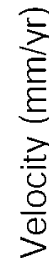
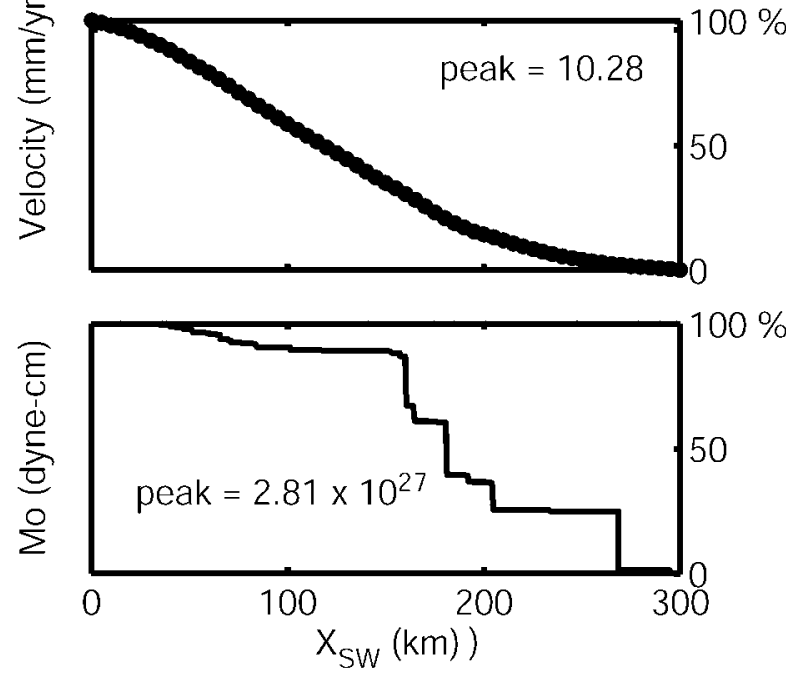

(b) Region $B$
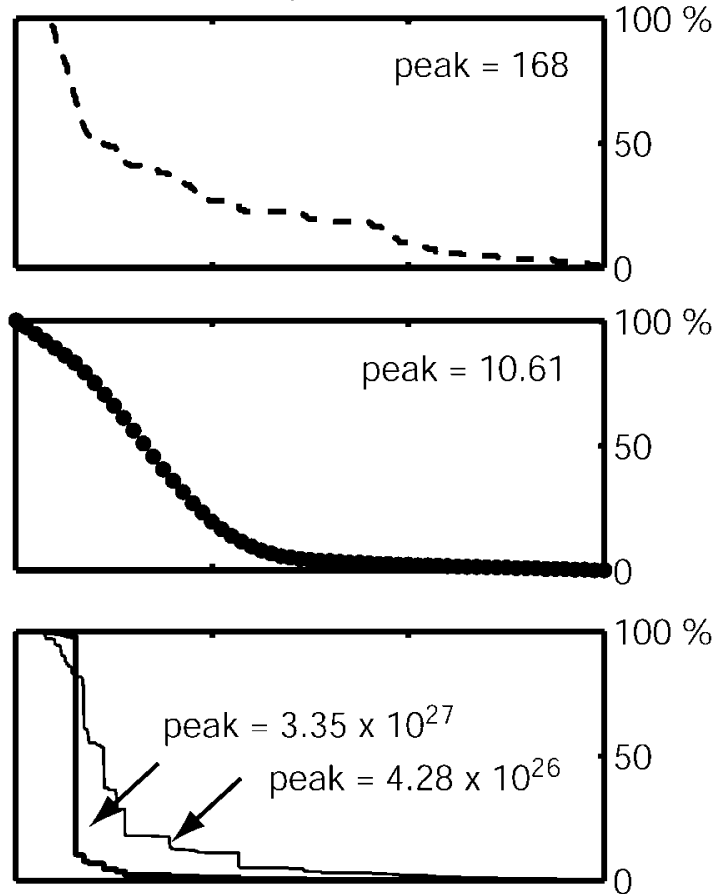

(d)

Region D
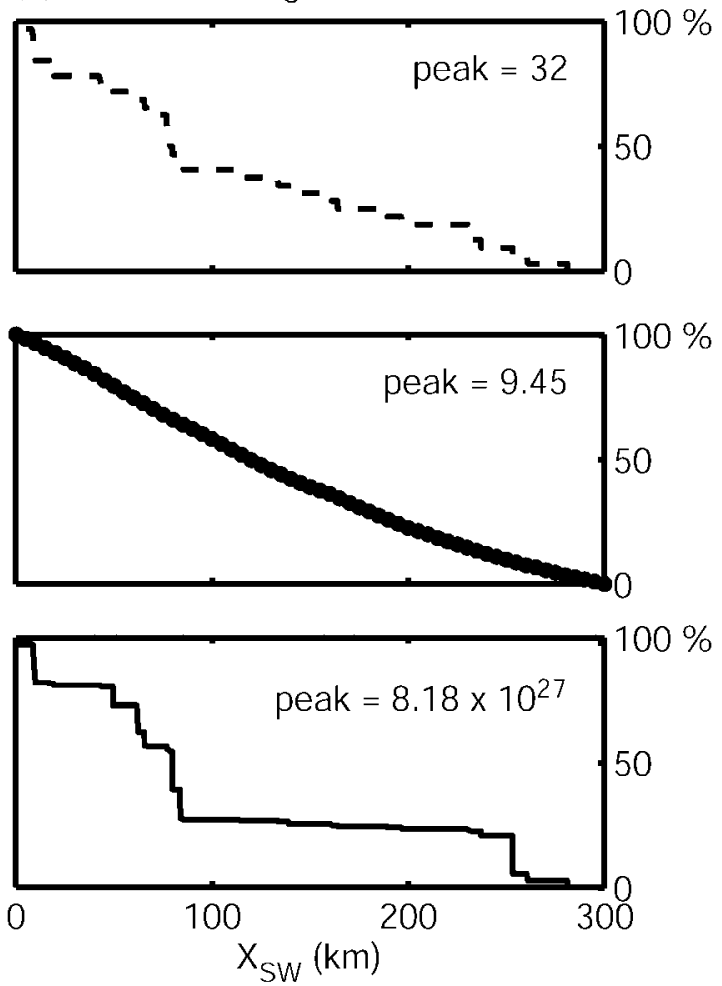

Figure 7. Profiles through domains A (a), B (b), C (c), and D (d) (Fig. 5), along the western edge of the province. Each domain extends $300 \mathrm{~km}$ inward from the edge of the study region. For each domain, the top plot shows the cumulative number of earthquake events within the domain and located at distances greater than $X_{\mathrm{SW}}$ from the southwest boundary. The center plot shows the magnitude of velocity from Figure 6 . The bottom plot shows cumulative seismic moment release of all events within the domain located at a distance greater than $X_{\mathrm{SW}}$ from the southwestern boundary of the study region (Fig. 5). The thin line in Figure $7 \mathrm{~b}$ gives the cumulative moment release with the $M_{\mathrm{W}} 7.58$ Owens Valley event removed. Right axes of each graph show normalized values. 
Table 4

Statistical Distribution of Seismic-Moment Rates (dyne cm/yr) Determined from Historical Seismicity

\begin{tabular}{lcrrrr}
\hline & Slip Predictable & Average Since 1871 & End Points & Least Squares & Time Predictable \\
\hline Magnitude & \multicolumn{5}{c}{ Visual Approach } \\
Method A & $6.15 \times 10^{25}$ & $8.52 \times 10^{25}$ & $7.64 \times 10^{25}$ & $6.85 \times 10^{25}$ & $8.84 \times 10^{25}$ \\
Method B & $4.32 \times 10^{25}$ & $5.83 \times 10^{25}$ & $5.21 \times 10^{25}$ & $4.51 \times 10^{25}$ & $5.75 \times 10^{25}$ \\
Method C & $7.72 \times 10^{25}$ & $11.25 \times 10^{25}$ & $10.07 \times 10^{25}$ & $8.86 \times 10^{25}$ & $14.91 \times 10^{25}$ \\
Method D & $6.64 \times 10^{25}$ & $9.28 \times 10^{25}$ & $8.68 \times 10^{25}$ & $7.48 \times 10^{25}$ & $9.06 \times 10^{25}$ \\
Statistics & \multicolumn{5}{c}{ Rates determined from 5000 Monte Carlo Simulations } \\
Minimum & $4.69 \times 10^{25}$ & $6.37 \times 10^{25}$ & $5.74 \times 10^{25}$ & $5.02 \times 10^{25}$ & $6.12 \times 10^{25}$ \\
Maximum & $7.67 \times 10^{25}$ & $10.94 \times 10^{25}$ & $9.80 \times 10^{25}$ & $8.72 \times 10^{25}$ & $14.59 \times 10^{25}$ \\
Mean & $6.18 \times 10^{25}$ & $8.69 \times 10^{25}$ & $7.81 \times 10^{25}$ & $6.90 \times 10^{25}$ & $10.33 \times 10^{25}$ \\
Std. Dev. & $0.41 \times 10^{25}$ & $0.72 \times 10^{25}$ & $0.64 \times 10^{25}$ & $0.53 \times 10^{25}$ & $1.28 \times 10^{25}$ \\
\hline
\end{tabular}

The magnitude assignments of events within the catalog were varied to help quantify and assess the uncertainties associated with the seismic-moment release. For Method A, the preferred catalog is used for which the best moment estimates of each event in the catalog are used to define the moment release (see Fig. 9). In Method $\mathrm{B}$, the smallest moment estimates of the 10 largest events are used, whereas for Method $\mathrm{C}$ the largest moment estimates of the 10 largest events are used. For Methods A, B, and C, the moderate events were held at their preferred values, usually the smallest catalog estimate. For Method D, moderate events were assigned to the maximum catalog magnitude recorded, with the magnitudes of the largest events held at preferred values. This yields an upper-bound estimate for the occurrence rate of moderate earthquakes.

(b)

\section{Longitude}

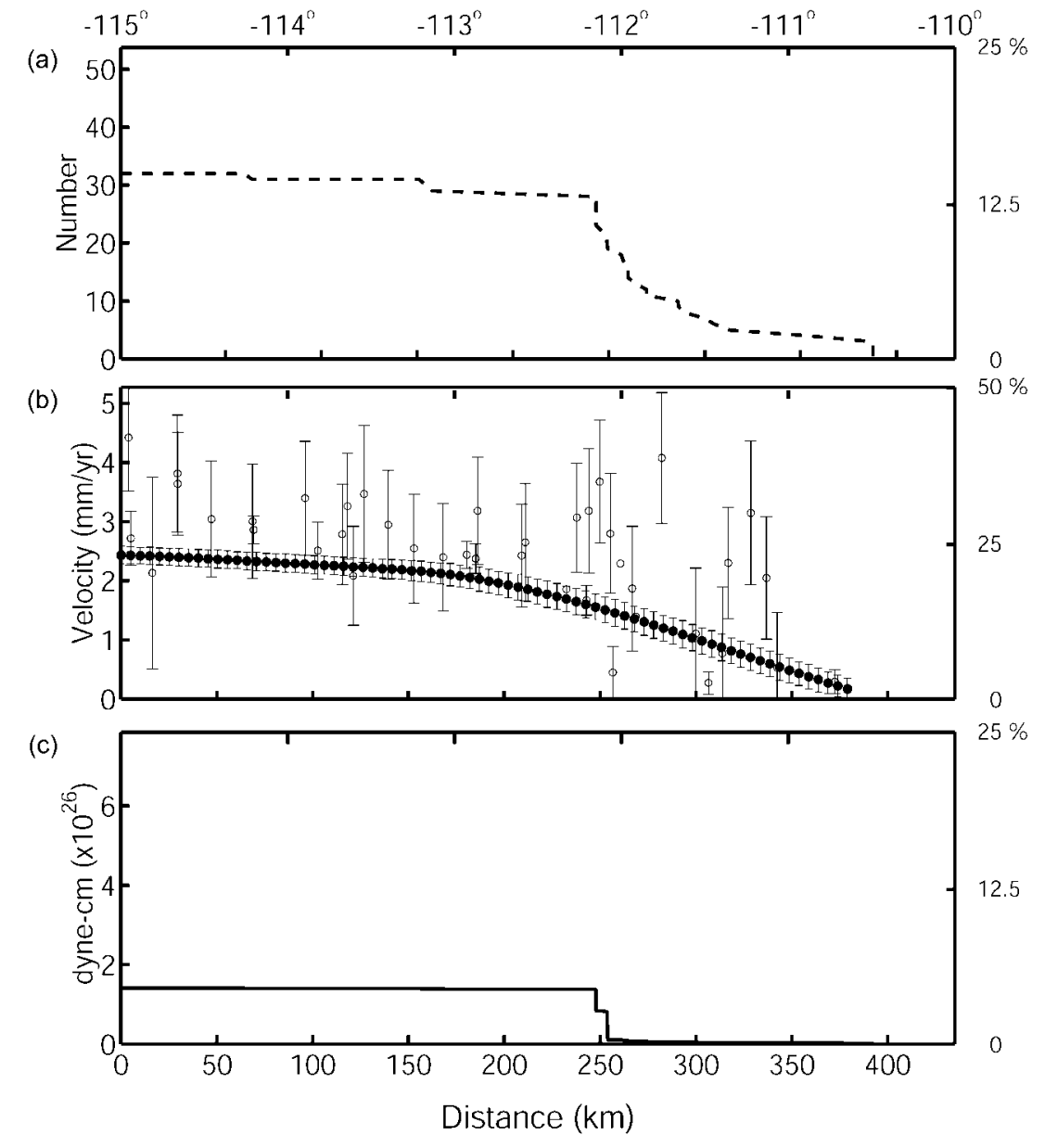

Figure 8. Profiles through the eastern domain (Fig. 5) (a) Cumulative number of earthquake events within the domain, (b) the magnitude of velocity determined from inversion of geodetic data through the center of the domain, and (c) cumulative seismic-moment release within the domain, as a function of the east-west distance. Modeled velocities are shown (filled circles) along with one-standarddeviation error bars. Data used to derive the model are also shown (open circles) as well as their one-standard-deviation error limits. Scales along the ordinate axes are normalized by the largest values in the total study region for the latitude range of this domain. 


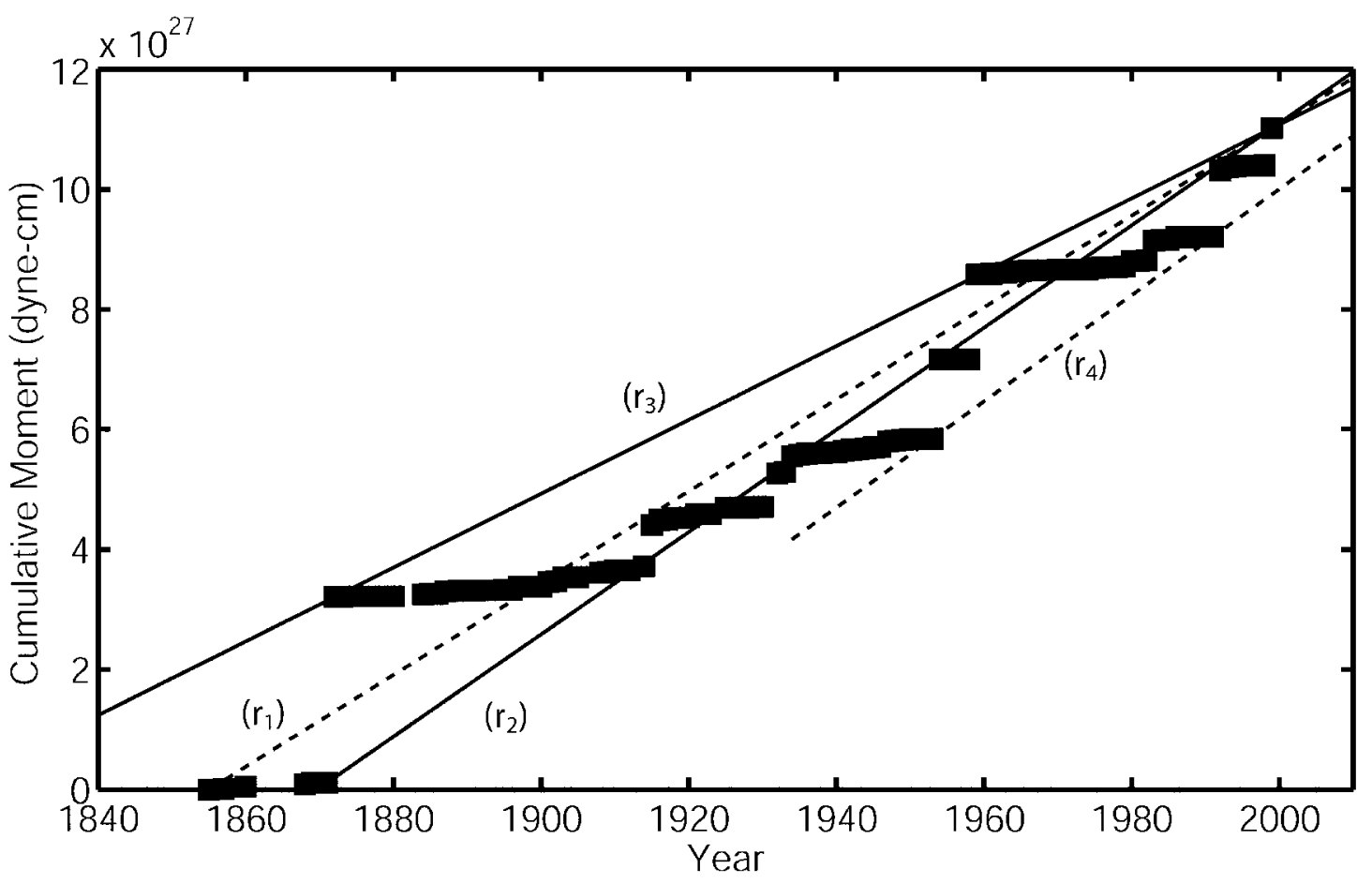

Figure 9. Plot of cumulative seismic-moment release with time over the study region, based on preferred moment estimates for each earthquake. Lines show possible release rates: $r_{1}$ gives an average rate since $1857\left(7.64 \times 10^{25}\right.$ dyne $\left.\mathrm{cm} / \mathrm{yr}\right) ; r_{2}$ gives an average rate since $1871\left(8.52 \times 10^{25}\right.$ dyne $\left.\mathrm{cm} / \mathrm{yr}\right) ; r_{3}$ gives the slip-predictable bound $\left(6.15 \times 10^{25}\right.$ dyne $\left.\mathrm{cm} / \mathrm{yr}\right)$; and $r_{4}$ gives the time-predictable bound $(8.84 \times$ $10^{25}$ dyne $\mathrm{cm} / \mathrm{yr}$ ). The time- and slip-predictable models of moment release usually apply to a single fault, and extending the concepts to a region with multiple faults does not have the physical relationship to stress and friction as in the model by Shimazaki and Nakata (1980).

smaller events, (2) using smallest and largest moment estimates for the 10 largest events, and (3) using Monte Carlo realizations of the moments of the 10 largest events randomly distributed between the smallest and the largest values. As the estimate of moment rates is least sensitive to the range of uncertainty of the 790 smaller events in the catalog (of the total of 800), we focused on the uncertainties associated with the 10 largest events. Results are given in Table 4.

The procedure in Figure 9 was automated and repeated for randomly chosen moments of the 10 largest earthquakes for the Monte Carlo approach. The moment release for each of these events was randomly selected, assuming a constant probability density between minimum and maximum $M_{\mathrm{w}}$ estimates. The maximum and minimum $M_{\mathrm{w}}$ values were selected based on the most reliable and appropriate estimates of $M_{\mathrm{w}}$ from the literature (Appendix 1, Table 2). Moment release for the 790 smaller earthquake events was held constant at the favored values. A total of 50,000 Monte Carlo realizations was generated. The distributions of rates from these realizations are shown in Figure 10 and summarized in Table 4. Considering one standard deviation about the mean values and the full set of fitting approaches, the most likely historical moment rate ranges from $5.8 \times 10^{25}$ to 11.3 $\times 10^{25}$ dyne $\mathrm{cm} / \mathrm{yr}$ determined from averaging since 1871 . The extremes are $4.3 \times 10^{25}$ to $14.9 \times 10^{25}$ dyne $\mathrm{cm} / \mathrm{yr}$.

\section{Geodetic Moment Rates}

The range of moment rates, determined previously, can be compared with moment rates that can be estimated from the geodetic deformation rates. To do this we need models that relate the deformation rates to moment rates, which is nonunique. Acknowledging the nonuniqueness and uncertainty involved with converting surface strain to a scalar moment rate, this study utilizes four methods (Anderson, 1979; Ward, 1998a, 1998b; Working Group on California Earthquake Probabilities, 1995; Savage and Simpson, 1997) to help quantify the moment rate from geodesy and its associated errors. These are listed in Table 5. Table 5 shows that for uniaxial strain (e.g., in the $x_{2}$ direction) the four methods are very similar. Anderson (1979) is different from the other three because he proposed an adjustment for inefficient fault orientations (parameter $k$ ), whereas the other three methods estimate the minimum rate.

The moment rate estimate from geodetic strain rates is 


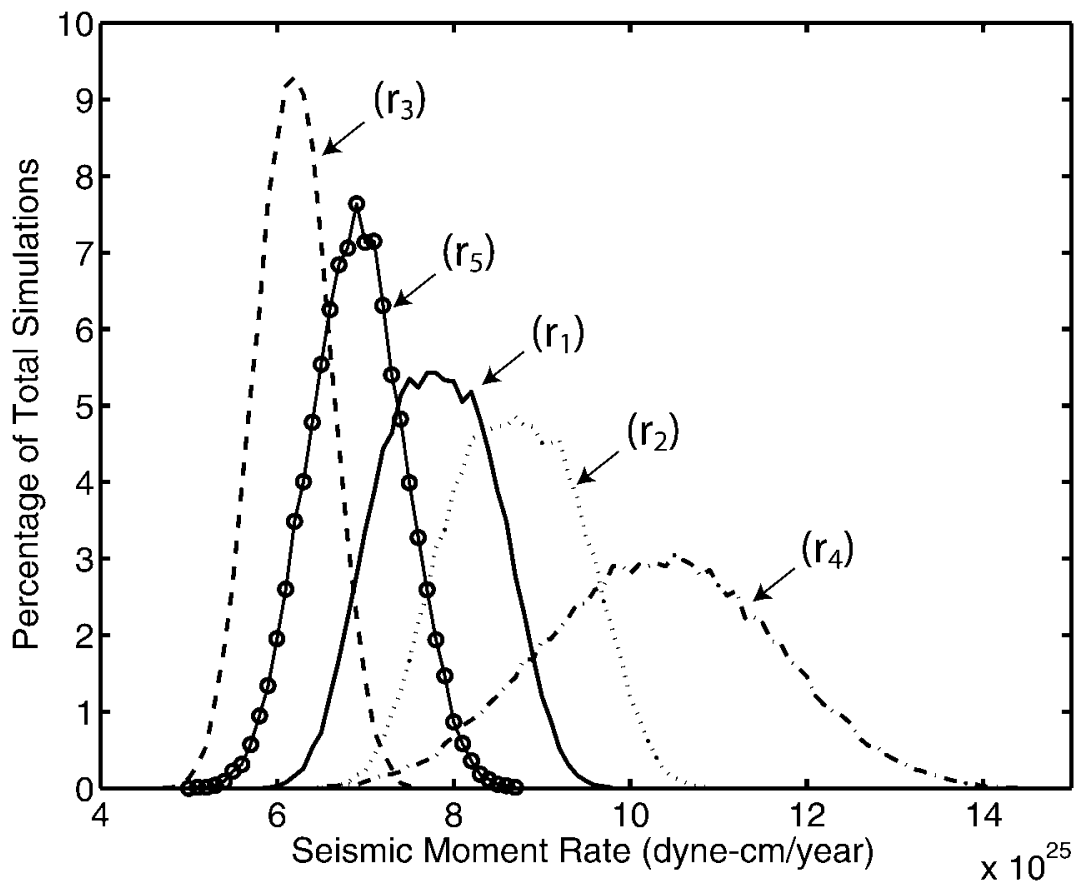

Figure 10. Distribution of the average seismic moment rate since $1857\left(r_{1}\right)$ and $1871\left(r_{2}\right)$ as well as the slip $\left(r_{3}\right)$ and time-predictable $\left(r_{4}\right)$ bounds of the seismic-moment rates determined from 50,000 Monte Carlo simulations. The distribution designated as $r_{5}$, not shown on Figure 9, is derived from a least-squares fit to the cumulative moments, with each year contributing one data point. The bin width is $0.1 \times 10^{25}$ dyne $\mathrm{cm} / \mathrm{yr}$.

Table 5

Moment Rates from Geodesy

\begin{tabular}{lll}
\hline Method & Equation & $\begin{array}{c}\text { Moment Rate } \\
\text { (dyne cm/yr) }\end{array}$ \\
\hline Anderson $(1979)^{*}$ & $\dot{M}_{0}=2 \mu \Sigma W \dot{\varepsilon}_{2} / k$ & $6.93 \times 10^{25}$ \\
Ward $(1994,1998 \mathrm{a}, 1998 \mathrm{~b})^{\dagger}$ & $\dot{M}_{0}=2 \mu W \Sigma_{\max }\left(\left|\dot{\varepsilon}_{1}\right|,\left|\dot{\varepsilon}_{2}\right|\right)$ & $5.20 \times 10^{25}$ \\
Working Group $(1995)^{\sharp}$ & $\dot{M}_{0}=2 \mu W \Sigma\left(\dot{\varepsilon}_{1}-\dot{\varepsilon}_{2}\right)$ & $3.91 \times 10^{25}$ \\
Savage and Simpson $(1997)^{\S}$ & $\dot{M}_{0}^{(\min )}=2 \mu W \Sigma_{\max }\left(\left|\dot{\varepsilon}_{1}\right|,\left|\dot{\varepsilon}_{2}\right|,\left|\dot{\varepsilon}_{1}+\dot{\varepsilon}_{2}\right|\right)$ & $5.25 \times 10^{25}$ \\
\hline
\end{tabular}

*Anderson (1979) suggests a best estimate modeling a volume extending or contracting in one direction (say $x_{2}$ ), where $\mu$ is the shear modulus, $\Sigma$ is the surface area of the region (generalized from the product $L_{1} L_{2}$ in his article, where $L_{1}$ is the length of the region, $L_{2}$ is the width of the region in the direction that it is straining), $W$ is the seismogenic thickness. $\dot{\varepsilon}_{2}=V_{2} / L_{2}$ is the strain rate, where $V_{2}$ is the relative extension or convergence velocity of the opposite sides of the region. Parameter $k$ is a dimensionless constant that adjusts for the inefficiency of randomly oriented faults to accommodate strain.

${ }^{\dagger}$ Ward $(1994,1998 \mathrm{a}, 1998 \mathrm{~b})$ proposes a minimum rate that incorporates the maximum eigenvalue, that is, the principle horizontal extension and contraction rates, $\dot{\varepsilon}_{1}$ and $\dot{\varepsilon}_{2}$, where $\Sigma$ is the surface area of the region. Other symbols are as in footnote *.

"The Working Group on California Earthquake Probabilities (1995) also uses a minimal approach to represent the moment rate tensor, utilizing the difference between the principal strain rates. Symbols are as in footnote *.

${ }^{\S}$ Savage and Simpson (1997) also suggest a minimum rate, accommodating strain in multiple directions. Symbols are as in footnote *.

If strain is only in the $x_{2}$ direction the strain-rate terms are identical for all four methods. Anderson's (1979) equation then converges to these equations when $k=1$ and is about $33 \%$ larger for $k=0.75$.

proportional to the chosen seismogenic thickness. To choose the most appropriate thickness, depth distributions of microearthquakes from catalog listings from Nevada and Utah were utilized. Cumulative frequency plots of depth distribution of microearthquakes (Fig. 11) from general catalogs show that $98 \%$ of events occur at depths less than $15 \mathrm{~km}$ for the entire Utah (1962-1999) region and $17 \mathrm{~km}$ for the Nevada region (1990-1999). Time intervals for data presented in Figure 11 were selected based on station coverage. Previous studies have investigated the seismogenic depth for
Utah in more detail. Based on well-constrained focal depths, $15 \mathrm{~km}$ is the preferred source depth used by Wong et al. (2001) for Utah. Arabasz et al. (1992) found a north-south dependence in focal depth distributions along the Wasatch Front with $99 \%$ of events occurring at $17 \mathrm{~km}$ in the south, to $11 \mathrm{~km}$ in the north. Considering the preceding studies and Figure 11, we assume all deformation occurs seismically above an average brittle-ductile transition depth of $W=$ $15 \mathrm{~km}$ for the entire study region. The uncertainty introduced by this assumption is probably under $20 \%$. 


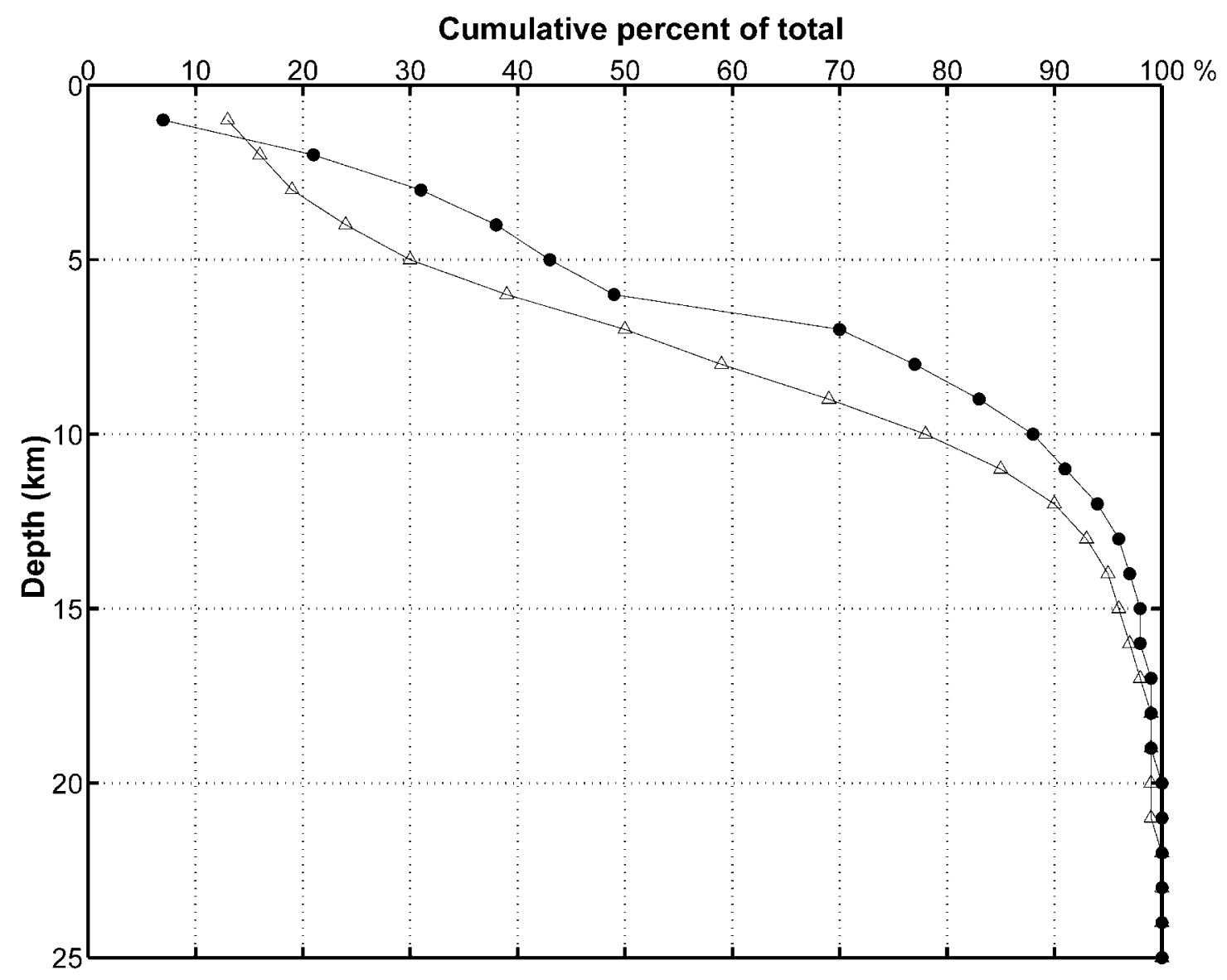

Figure 11. Depth distribution of earthquakes within Nevada (triangles) and Utah (circles).

Table 6

Comparison of Moment Rates for the Basin and Range Province

\begin{tabular}{llr}
\hline & \multicolumn{1}{c}{ Data/Method* } & \multicolumn{1}{c}{$\begin{array}{c}\text { Moment Rate } \\
(\text { dyne cm/yr) }\end{array}$} \\
\hline 1. Seismicity & $\begin{array}{l}\text { Average since 1971 } \\
\text { (most likely range) }\end{array}$ & $5.83-11.25 \times 10^{25}$ \\
& Extreme values & $4.32-14.91 \times 10^{25}$ \\
2. Geodesy & & $3.91-6.93 \times 10^{25}$ \\
3. Geology & USGS 2002/1996 data $\dot{M}_{0}=\mu A s$ & $2.55 \times 10^{25}$ \\
\hline
\end{tabular}

*Assuming $\mu=3 \times 10^{11}$ dyne $\mathrm{cm}^{2}$ for geodesy and geology, and $W=15 \mathrm{~km}$ for all.

We predict the moment rate for the Basin and Range province from the regional geodetic strain rate tensor models introduced earlier (Table 5), using a shear modulus of $\mu=3$ $\times 10^{11}$ dyne $\mathrm{cm}^{2}, W=15 \mathrm{~km}$, and $k=0.75$ (Anderson, 1979). Resulting moments from geodesy are in the range from $3.91 \times 10^{25}$ to $6.93 \times 10^{25} \mathrm{dyne} \mathrm{cm} / \mathrm{yr}$.

\section{Geological Moment Rates}

To determine the geological moment release rate we utilize fault parameters used as input to the 1996 and 2002
USGS seismic hazard maps (Frankel et al., 1996, 2002; Haller et al., 2002). Data for California come from the 1996 model, whereas all other data for the study region come from the 2002 model (Haller et al., 2002). Although improvements in geological fault characterizations are ongoing, the USGS database represents an important landmark and plays a key role in national building codes. The resulting geological moment rate for the region is $2.55 \times 10^{25}$ dyne $\mathrm{cm} / \mathrm{yr}$.

\section{Comparison of Moment Rates}

Moment rates from the seismic, geodetic, and geological methods are compared in Table 6 and Figure 12. As discussed previously these moment rates are intended to display the full range of uncertainties. Thus we believe that the results in Figure 12 are a robust comparison of these differing techniques which we later use to infer the long-term seismicity rate. Within uncertainties, seismic and geodetic rates are in agreement. Geological rates are much lower than the seismicity and geodetic rates. This is not surprising considering the limiting paleoseismic data, which are necessarily based only on faults that have been well characterized, a minority of all the faults in the Basin and Range. 


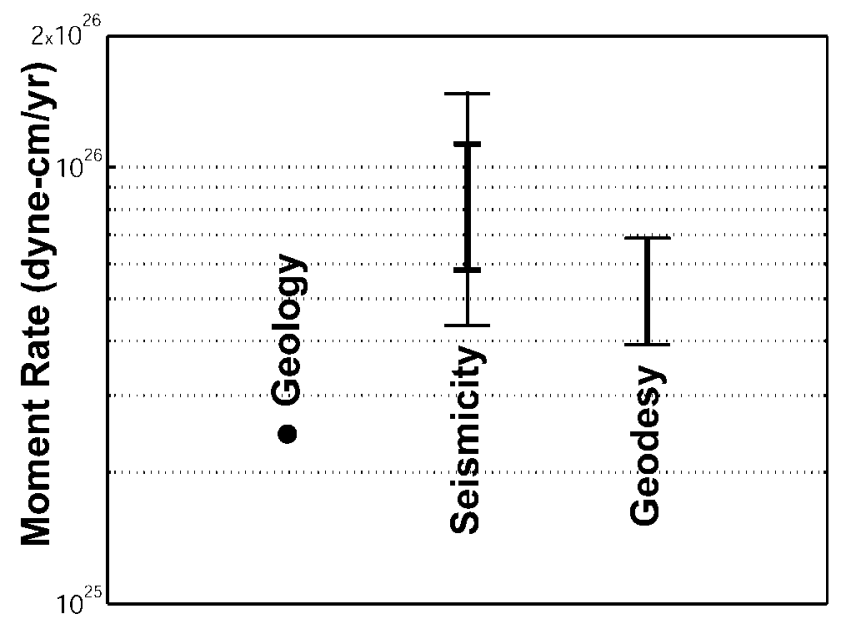

Figure 12. Comparison of the range of moment rates determined from the historical seismicity with those determined from geodesy and geology (Table 6). Both the extreme values (thin line) and the most likely bounds (thick line) on the seismicity rate are shown.

\section{Maximum Magnitude for the Great Basin}

We consider whether recent suggestions in the literature regarding the maximum magnitude of earthquakes within the Basin and Range are consistent with our results.

Anderson and Luco (1983) related three functional forms of the Gutenburg-Richter curves to the moment rate. These models depend on (1) the rate of occurrence at a reference magnitude, (2) a $b$-value, and (3) the maximum magnitude $M_{\max }$. Major differences among the models occur in the way they are truncated as they approach $M_{\max }$. The integral of the area under these curves defines the moment release rate, based on the specified frequency-magnitude relationship. Note that these models are not physical laws to which earthquake statistics must ultimately conform. However, assuming that the frequency-magnitude distribution characterized by the seismic catalog is representative of the region, we apply these curves to the current catalog (1) to determine which of the Anderson and Luco (1983) models is most representative of the Basin and Range seismicity and (2) to determine what values of $M_{\max }$ come out of fitting each of these curves to the observations.

We compare the historical cumulative magnitude distribution (Fig. 4b) with the Anderson and Luco (1983) models (Fig. 13). The curves are normalized using a moment release rate of $11.3 \times 10^{25}$ dyne $\mathrm{cm} / \mathrm{yr}$, corresponding to the upper limit of our most likely historical moment rate range obtained from the historical seismicity. Increasing $M_{\max }$, while continuing to match a moment release rate of $11.3 \times 10^{25}$ dyne $\mathrm{cm} / \mathrm{yr}$, results in lowering of the curves. The comparison of these models to the historical $b$-value curve indicates that model 1 best matches the data when $M_{\max } 7.58$, model 2 matches when $M_{\max } 8.0$, and model 3 matches when $M_{\max }$ 8.2. Lowering the moment release rate to $5.8 \times 10^{25}$ dyne $\mathrm{cm} / \mathrm{yr}$ lowers the curve requiring $M_{\max } 6.8$ for model 1 to satisfy the historical seismicity, whereas models 2 and 3 fail to fit the high-magnitude end of the curve.

Models 2 and 3 appear to match the cumulative moment curve better than model 1 in Figure 13. However, at lowoccurrence rates the shape of the curve determined by data is poorly constrained given the duration of observations. We feel that there is not sufficient data to determine which model best characterizes Basin and Range seismicity rates.

With consideration of moment rates from historical seismicity and geodesy, the Anderson and Luco (1983) models imply that there is no reason to expect an earthquake in the Great Basin with magnitude greater than $M_{\max } \approx 8.2$. This is inconsistent with the suggestions of Wernicke (1995) and Kagan (1999), through separate lines of research, that the region could experience earthquakes of magnitudes much greater than eight. Kagan (1999) proposed a universal magnitude-frequency distribution in which the $b$-values and maximum moment is the same for all continental regions. He proposed that for shallow earthquakes the universal value of the effective maximum moment magnitude is of the order 8.5-9.0. As shown previously, this magnitude is inconsistent with the historical earthquake rates. An earthquake of this size also runs into difficulty on physical grounds. Consider for instance that an event with $M_{\mathrm{w}} 8.5$ has, by equation (3), a seismic moment of $7 \times 10^{28}$ dyne $\mathrm{cm}$. To maximize the fault area and shear modulus, we consider values larger than those used previously: $\mu=4 \times 10^{11}$ dyne $\mathrm{cm}^{2}$ and a dip of $45^{\circ}$ where the seismogenic thickness is $17 \mathrm{~km}$, yielding $W=24 \mathrm{~km}$. From the definition of seismic moment (equation 1), the product of fault length $(L)$ and mean slip $(D)$ for an event of this size will be about $L D=7300 \mathrm{~m} \mathrm{~km}$. A rupture on a fault of $300 \mathrm{~km}$ length (greater than any fault in the Great Basin) would need an average slip of $\sim 24 \mathrm{~m}$, which is larger than any observed historical rupture anyplace in the world. We thus conclude that the Kagan model is not reasonable, both on statistical and physical grounds.

Wernicke (1995) speculates that seismogenic low-angle normal faults that form the base of the entire seismogenic zone play an important role in accommodating Basin and Range extension. He further speculates that these faults have longer recurrence intervals than steeply dipping faults because they fail in infrequent, extremely large magnitude events. Wernicke suggests that the hypothesized ability of low-angle normal faults at the base of the crust to generate large events with greater magnitudes has not been tested globally because of the short historical records. Although low-angle normal faults have been imaged in the Basin and Range province (Allmendinger, 1983; Abbott et al., 2001), there is no evidence there or elsewhere that such structures experience brittle failure. A common expectation is that the extension of the region occurs by creep on these faults below the brittle-ductile transition. If the Wernicke speculation is correct, then the stress accumulation would roughly double the seismic-moment rate from the estimates given previously, and the statistical argument would allow $M_{\max }$ to increase to about 8.2. However, evidence for accommodating 


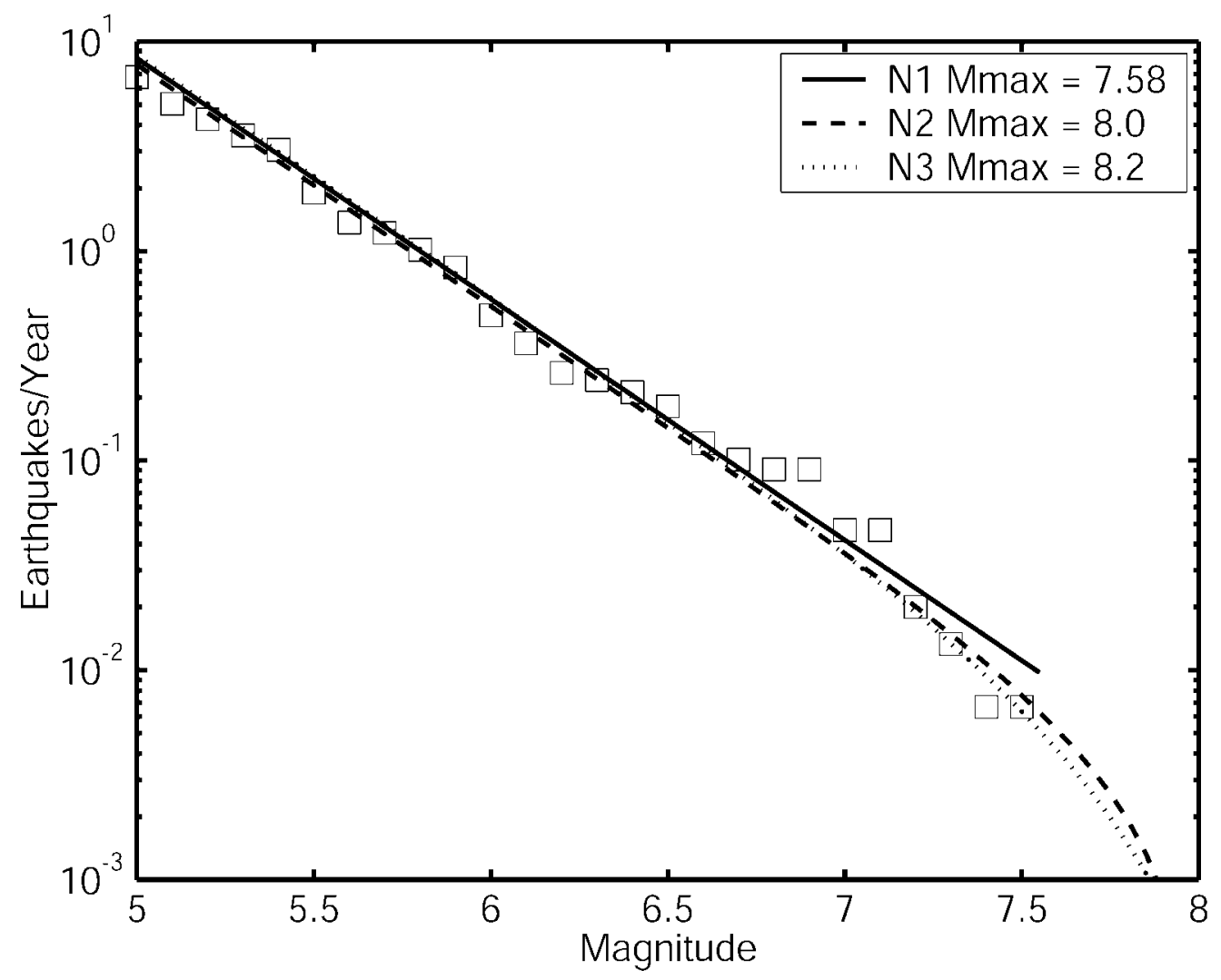

Figure 13. Cumulative earthquake occurrence rates $[N(\mathrm{~m})]$ for the three functional forms of the Gutenburg-Richter curves of Anderson and Luco (1983), using $b=1.00$ Figure $4 \mathrm{~b}$. These models depend on (1) $N_{1}=10^{a-b M} H\left(M_{\max }-M\right)$ the rate of occurrence at a reference magnitude, (2) $n_{2}=-d N_{2} / d M=10^{a-b M} H\left(M_{\max }=M\right)$ a $b$-value, and (3) $n_{3}=-d N_{3} / d M=\left(10^{a-b M}-10^{a-b M_{\max }}\right) H\left(M_{\max }=M\right)$ the maximum magnitude, $M_{\max }$. The plots have been normalized using a moment-release rate of 11.3 $\times 10^{25}$ dyne $\mathrm{cm} / \mathrm{yr}$ corresponding to the most likely maximum estimate determined from historical seismicity. To match the moment release rate $M_{\max }$ is set to 7.58 , the largest event in the catalog for $N_{1}, M_{\max }=8$ for $n_{2}$, and $M_{\max }=8.2$ for $n_{3}$.

extension by a creep mechanism (Buck et al., 2003) at the strain rates present in the Great Basin suggests that this model is unlikely.

\section{Discussion and Conclusions}

The moment rate of earthquakes implied by geodesy is consistent with the historical seismic estimate. The extremes on the range of moment rate from historical seismicity, based on mean rates and on linear upper and lower bounds for the cumulative moment curves allowing for uncertainties in the moments of the controlling earthquakes, are $4.3 \times 10^{25}$ to $14.9 \times 10^{25}$ dyne $\mathrm{cm} / \mathrm{yr}$. The most likely rate is between $5.8 \times 10^{25}$ to $11.3 \times 10^{25}$ dyne $\mathrm{cm} / \mathrm{yr}$. This overlaps the range determined from the geodetic data, $3.9 \times 10^{25}$ to $6.9 \times 10^{25}$ dyne cm/yr (Fig. 12). This suggests that the rate of historic earthquakes within the Basin and Range province, taken as a whole, is the rate that should be expected in the future.

Uncertainties in estimates of moment rates do not arise only on the seismicity side. Geodetic and seismic measurements sample different aspects of the deformation field. Seismicity and geological estimates serve only as a record of brittle deformation, whereas geodesy encompasses both seismic and aseismic strain accumulation. Recently, significant aseismic deformation has been observed below Lake Tahoe, California (Smith et al., 2004), demonstrating the importance of aseismic strain in the Great Basin. Geodetic rates cannot uniquely determine slip at depth (Savage and Simpson, 1997) and may only give a measure of the instantaneous strain transients, which may not be preserved throughout the earthquake cycle (Savage and Lisowski, 1998; Shen-Tu et al., 1999). Recent geodetic observations have shown that historical moment release has occurred where contemporary strain is accumulating (Hammond and Thatcher, 2004). Whether the geodetic signature is representative of longterm deformation is argued by Thatcher (1995) to depend on fault characteristics and spacing, the extent of the cyclic zone, and whether the geodetic network completely spans the entire deforming zone. Geodetic measurements may 
therefore be sensitive to the duration and sampling of deformation with agreement also dependent on whether the sample period covered includes earthquakes that contributed significant post and coseismic displacements to the observed geodetic velocities. Apart from these uncertainties due to Earth processes, additional uncertainties are introduced in the processing decisions in converting individual GPS measurements to regional strain-rate models. These uncertainties become more important as the size of the region decreases. The final geodetic uncertainty arises in converting strain rates to seismic moment rates.

We suggest that it is possible to expand on and quantify the suggestions of Smith (1976) and Ward (1998a) that the adequacy of seismic catalogs to estimate earthquake recurrence rates depends on the area of the region, catalog duration, and regional strain rates. Where Smith looked at the product of time and length of the seismic zone, and Ward looked at the product of time and strain rate, we suggest that it is useful to define a catalog adequacy parameter

$$
Z=T \Sigma \overline{\dot{\varepsilon}}
$$

defined as the product of the duration of the earthquake record $(T)$, the area of the region, and the average strain rate, $\overline{\dot{\varepsilon}}$, as estimated by space geodetic methods. For a given strain rate, as the size of the region decreases, a longer catalog duration is needed. It should be obvious that the parameter becomes meaningless if the region is too small to contain a characteristic earthquake. There is no requirement that the strain be distributed uniformly within the region. For the Basin and Range, $T=146$ years, $\Sigma=7.25 \times 10^{5} \mathrm{~km}^{2}$, and, for the region as a whole $\overline{\dot{\varepsilon}} \approx V / L=1.3 \times 10^{-8} / \mathrm{yr}$, where the slip rate $V=13 \mathrm{~mm} / \mathrm{yr}$ is the relative velocity of the Sierra Nevada block relative to stable North America, and $L=1000 \mathrm{~km}$ is the average width of the region. These parameters yield $Z \approx 1.38 \mathrm{~km}^{2}$. For the domains A-D (Fig. 5 ), using the same procedure, $Z \sim 0.1-0.25$, and since within these areas the historical and geodetic methods do not agree well (Fig. 7), these values of $Z$ are apparently too small. Based on these Basin and Range results, it seems reasonable to expect that in other regions with $Z \geq 1.5 \mathrm{~km}^{2}$, historical seismicity and geodesy will agree within uncertainties, although of course more testing is needed to confirm this hypothesis.

The spatial consistency of the distribution of small earthquakes, deformation, and moment release shown in Figure 7 is interesting. Given the shortness of the catalog duration and variability in absolute rates, spatial similarity between geodetic deformation and seismicity is not necessarily expected. Even in domain B (Fig. 7b), where the moment release is highly concentrated in the Owens Valley because of the $1872 M_{\mathrm{W}} 7.74$ Owens Valley earthquake, the spatial distribution of moderate earthquakes follows a broader curve similar to the deformation. Considering the uncertainties in estimates of the spatial distribution of the seismic hazard from historical seismicity, geodesy, and ge- ology, consistency of more than one of these techniques is a key factor in providing confidence for how seismic hazards are localized. We suggest that it is worthwhile to investigate conditions for the similarity of seismicity and geodesy to hold and consider that it is possible that some criteria based on a catalog adequacy, or related, parameter might be possible.

\section{Acknowledgments}

We thank Feng Su, Steve Wesnousky, Bob Wallace, Timothy Dixon, Roland Bürgmann, and Bill Hammond for helpful comments and suggestions, as well as anonymous reviewers who have reviewed this manuscript. Andrew Barron helped with the compilation of Figure 1. This research was supported by the U.S. Geological Survey National Earthquake Hazards Reduction Program under award 01HQGR0012.

\section{References}

Abbott, R., J. N. Louie, S. J. Caskey, and S. Pullammanappallil (2001). Geophysical confirmation of low-angle normal slip on the historically active Dixie Valley Fault, Nevada, J. Geophys. Res. 106, 4169-4181.

Allmendinger, R. W., J. W. Sharp, D. Von Tish, L. Serpa, L. Brown, S. Kaufman, J. E. Oliver, and R. B. Smith (1983). Cenozoic and Mesozoic structure of the eastern Basin and Range Province, Utah, from COCORP seismic-reflection data, Geology 11, 532-536.

Anderson, J. G. (1979). Estimating the seismicity from geological structure for seismic-risk studies, Bull. Seism. Soc. Am. 69, 135-158.

Anderson, J. G. (2003). Strong-motion seismology, in International Handbook of Earthquake and Engineering Seismology, W. H. K. Lee, H. Kanamori, P. C. Jennings, and C. Kisslinger (Editors), Vol. 81B, Academic Press, Amsterdam, 937-905.

Anderson, J. G., and J. E. Luco (1983). Consequences of slip rate constraints on earthquake occurrence relations, Bull. Seism. Soc. Am. 73, 471-496.

Arabasz, W. J., J. C. Pechmann, and E. D. Brown (1992). Observational seismology and the evaluation of earthquake hazards and risk in the Wasatch Front area, Utah, Assessment of Regional Earthquake Hazards and Risk along the Wasatch Front, Utah, P. L. Gori and W. W. Hays (Editors), in U.S. Geol. Surv. Profess. Pap., 1500-A-J, D1-D36.

Barker, J. S., and T. C. Wallace (1986). A note on the teleseismic body waves from the 23 November 1984 Round Valley, California, earthquake, Bull. Seism. Soc. Am. 76, 883-888.

Barker, M. R., and D. I. Doser (1988). Joint inversion of regional and teleseismic earthquake waveforms, J. Geophys. Res. 93, 2037-2045.

Barrientos, S. E., S. N. Ward, J. Gonzalez-Ruiz, and R. S. Stein (1985). Inversion for moment as a function of depth from geodetic observations and long period body waves of the Borah Peak, Idaho, earthquake, Workshop XXVIII on the Borah Peak earthquake, U.S. Geol. Surv. Open-File Rept. 85-290, 485-518.

Beanland, S., and M. M. Clark (1993). Late Quaternary history of the Owens Valley fault zone, eastern California and surface rupture associated with the 1872 earthquakes (abstracts with programs), Geol. Soc. Am. 25, 7.

Bennett, R. A., B. P. Wernicke, N. A. Niemi, and M. Friedrich (2003). Contemporary strain rates in the northern Basin and Range province from GPS data, Tectonics 22, 1008, doi 10.1029/2001TC1355.

Boatwright, J., and G. L. Choy (1985). Teleseismic estimates of the energy radiated by shallow earthquakes, U.S. Geol. Surv. Open-File Rept. 85-290, 409-448.

Bolt, B. A., and R. D. Miller (1975). Catalogue of earthquakes in Northern California and adjoining areas, 1 January 1910-31 December 1972, Seismographic Stations, University of California, Berkeley, California. 
Brune, J. N. (1968). Seismic moment, seismicity, and slip rate along major fault zones, J. Geophys. Res. 73, 777-784.

Buck, W. R., L. L. Lavier, and A. Babeyko (2003). A numerical model of lithospheric extension producing fault-bounded basins and ranges, Int. Geol. Rev. 45, 712-723.

Caskey, S. J., S. G. Wesnousky, P. Zhang, and D. B. Slemmons (1996). Surface faulting of the 1954 Fairview Peak (Ms 7.2) and Dixie Valley (Ms 6.8) Earthquakes, Central Nevada, Bull. Seism. Soc. Am. 86, 761787.

Catchings, R. D., and W. D. Mooney (1991). Basin and Range and upper mantle structure northwest to central Nevada, J. Geophys. Res. 96, $6247-6267$.

Chulick, G. S., and W. D. Mooney (2002). Seismic structure of the crust and uppermost mantle of North America and adjacent oceanic basins: a synthesis, Bull. Seism. Soc. Am. 92, 2478-2492.

dePolo, C. M. (1998). A reconnaissance technique for estimating the slip rates of normal-slip faults in the Great Basin, and application to faults in Nevada, U.S.A., Ph.D. Dissertation, University of Nevada, Reno, $381 \mathrm{p}$.

dePolo, D., and C. M. dePolo (1999). Earthquakes in Nevada, 1852-1998, Nevada Bureau of Mines and Geology, Map 119.

dePolo, C. M., A. R. Ramelli, R. H. Hess, and J. G. Anderson (2003). Reevaluation of pre-1900 earthquakes in Western Nevada, NBMG Open-File Report, 2003-3, 208 pp.

Dixon, T. H., M. Miller, F. Farina, H. Wang, and D. Johnson (2000). Present-day motion of the Sierra Nevada block and some tectonic implications for the Basin and Range Province, North American Cordillera, Tectonics 19, 1-24.

Dixon, T. H., E. Norabuena, and L. Hotaling (2003). Paleoseismology and Global Positioning System; earthquake-cycle effects and geodetic versus geologic fault slip rates in the Eastern California shear zone, Geology 31, 55-58.

Dixon, T. H., S. Robaudo, J. Lee, and M. Reheis, (1995). Constraints on present-day Basin and Range deformation from space geodesy, Tectonics $14,755-772$.

Dokka, R. K., and C. J. Travis (1990). Role of the Eastern California Shear Zone in accommodating Pacific-North American plate motion, Geophys. Res. Lett. 17, 1323-1326.

Doser, D. I. (1985). Source parameters and faulting processes of the 1959 Hebgen Lake, Montana, earthquake sequence, J. Geophys. Res. 90, $4537-4555$.

Doser, D. I. (1986). Earthquake processes in the Rainbow MountainFairview Peak-Dixie Valley, Nevada, region 1954-1959, J. Geophys. Res. 91, 12,572-12,586.

Doser, D. I. (1987). Modeling the Pnl waveforms of the Fairview PeakDixie Valley, Nevada, U.S.A. earthquake sequence (1954-1959), Phys. Earth Planet. Interiors 48, 64-72.

Doser, D. I. (1988). Source parameters of earthquakes in the Nevada seismic zone, 1915-1943, J. Geophys. Res. 93, 15,001-15,015.

Doser, D. I. (1989a). Extensional tectonics in northern Utah-southern Idaho, U.S.A., and the 1934 Hansel Valley sequence, Phys. Earth Planet. Interiors 54, 120-134.

Doser, D. I. (1989b). Source parameters of Montana earthquakes (19251964) and tectonic deformation in the northern Intermountain seismic belt, Bull. Seism. Soc. Am. 79, 31-50.

Doser, D. I., and H. Kanamori (1987). Long-period surface waves of four western United States earthquakes recorded by the Pasadena strainmeter, Bull. Seism. Soc. Am. 77, 236-243.

Doser, D. I., and R. B. Smith (1982). Seismic moment rates in the Utah region, Bull. Seism. Soc. Am. 72, 525-551.

Doser, D. I., and R. B. Smith (1985). Source parameters of the 28 October 1983 Borah Peak, Idaho, Earthquake from Body Wave Analysis, Bull. Seism. Soc. Am. 75, 1041-1051.

Doser, D. I., and R. B. Smith (1989). An assessment of source parameters of earthquakes in the Cordillera of the western United States, Bull. Seism. Soc. Am. 79, 1383-1409.

Ekstrom, G., and A. M. Dziewonski (1985). Centroid-moment tensor so- lutions for 35 earthquakes in western North America (1977-1983), Bull. Seism. Soc. Am. 75, 23-40.

Flesch, L. M., W. E. Holt, A. J. Haines, and B. Shen-Tu (2000). Dynamics of the Pacific-North America plate boundary in the Western United States, Science 287, 834-836.

Frankel, A., C. Mueller, T. Barnhard, D. Perkins, E. Leyendecker, N. Dickman, S. Hanson, and M. Hopper. (1996). National seismic-hazard maps: documentation June 1996, U.S. Geol. Surv. Open-File Rept. 96-532, $110 \mathrm{p}$

Frankel, A. D., M. D. Petersen, C. S. Mueller, K. M. Haller, R. L. Wheeler, E. V. Leyendecker, R. L. Wesson, S. C. Harmsen, C. H. Cramer, D. M. Perkins, and K. S. Rukstales (2002). Documentation for the 2002 update of the national seismic hazard maps, U.S. Geol. Surv. Open-File Rept. 02-420.

Freymueller, J. T., M. H. Murray, P. Segall, and D. Castillo (1999). Kinematics of the Pacific North America plate boundary zone, northern California, J. Geophys. Res. 104, 7419-7441.

Haines, A. J., and W. E. Holt (1993). A procedure for obtaining the complete horizontal motions within zones of distributed deformation from the inversion of strain rate data, J. Geophys. Res. 98, 12,057-12,082.

Haller, K. M., R. L. Wheerler, and K. S. Rukstales (2002). Document of changes in fault parameters for the 2002 National Seismic Hazard Maps-Conterminous United States except California, U.S. Geol. Surv. Open-File Rept. 02-467.

Hammond, W. C., and W. Thatcher (2003). Crustal deformation of the northern Basin and Range from measurements with the Global Positioning System (abstract), EOS Trans. AGU 84, no. 46, Fall Meet. Suppl., G32B-07.

Hammond, W. C., and W. Thatcher (2004), Contemporary tectonic deformation of the Basin and Range province, western United States: 10 years of observation with the Global Positioning System, J. Geophys. Res. 109, B08403, doi 10.1029/2003JB002746.

Hammond, W. C., W. Thatcher, and G. Blewitt (2004). Crustal deformation across the Sierra Nevada-northern Walker Lane, Basin and Range transition, western United States Measured with GPS, 2000-2004 (abstract), EOS Trans., AGU 85, no.47, Fall Meet. Suppl., G31D-07.

Hanks, T. C., J. A. Hileman, and W. Thatcher (1975). Seismic moments of the larger earthquakes of the Southern California Region, Geol. Soc. Am. Bull. 86, 1131-1139.

Hanks, T. C., and H. Kanamori (1978). A moment magnitude scale, $J$. Geophys. Res. 84, 2348-2350.

Hart, R. S., R. Butler, and H. Kanamori (1977). Surface-wave constraints on the August 1, 1975, Oroville earthquake, Bull. Seism. Soc. Am. 67, no. 1, 1-7.

Hauksson, E., L. M. Jones, K. Hutton, and D. Eberhart-Phillips (1993). The 1992 Landers earthquake sequence: seismological observations, $J$. Geophys. Res. 98, 19,835-19,858.

Holt, W. E., B. Shen-Tu, J. Haines, and J. Jackson (2000). On the determination of self-consistent strain rate fields within zones of distributed deformation, in The History and Dynamics of Global Plate Motions, M. A. Richards, R. G. Gordon, and R. D. van der Hilst, (Editors), American Geophysical Union, Washington, D.C., 113-141.

Humphreys, E. D., and R. J. Weldon (1994). Deformation across the western United States: a local estimate of Pacific-North American transform deformation, J. Geophys. Res. 99, 19,975-20,010.

Ichinose, G. A., J. G. Anderson, K. D. Smith, and Y. Zeng (2003). Source parameters of Eastern California and Western Nevada Earthquakes from regional moment tensor inversion, Bull. Seism. Soc. Am. 93, $61-84$.

Ji, C., D. J. Wald, and D. V. Helmbereger (2002). Source description of the 1999 Hector Mine, California, Earthquake, Part II: Complexity of slip history, Bull. Seism. Soc. Am. 92, 1208-1226.

Jones, C. H., B. P. Wernicke, G. L. Farmer, J. D. Walker, D. S. Coleman, L. W. McKenna, and F. V. Perry (1992). Variations across and along a major continental rift: An interdisciplinary study of the Basin and Range Province, Western USA, Tectonophysics 213, 57-96. 
Kagan, Y. Y. (1999). Universality of the seismic moment-frequency relation, Pure Appl. Geophys. 155, 537-573.

Kanamori, H. (1977). The energy release in great earthquakes, J. Geophys. Res. 82, 2981-2987.

Kanamori, H. (1983). Magnitude scale and quantification of earthquakes, Tectonophysics 93, 185-199.

Kanamori, H., H.-K. Thio, D. Dreger, and E. Hauksson (1992). Initial investigation of the Landers, California, earthquake of 28 June 1992 using TERRAscope, Geophys. Res. Lett. 19, 2267-2270.

Kostrov, V. V. (1974). Seismic moment and energy of earthquakes, and seismic flow of rock, Earth Phys. 1, 23-40.

Kreemer, C., W. E. Holt, S. Goes, and R. Govers (2000). Active deformation in eastern Indonesia and the Philippines from GPS and seismicity data, J. Geophys. Res. 105, 663-680.

Kreemer, C., W. E. Holt, and A. J. Haines (2002). The global moment rate distribution within plate boundary zones, in Plate Boundary Zones Geodynamics Series 30, S. Stein and J. T. Freymueller (Editors), doi 10/1029/030GD10, American Geophysical Union, Washington, D.C., 173-190.

Langston, C. A., and R. Butler (1976). Focal mechanism of the August 1, 1975, Oroville earthquake, Bull. Seism. Soc. Am. 66, no. 4, 11111120.

Lavallée, D., G. Blewitt, P. J. Clarke, K. Nurutdinov, W. E. Holt, C. Kreemer, C. M. Meertens, W. S. Shiver, S. Stein, S. Zerbini, L. Bastos, and H.-G. Kahle (2001). GPSVEL project: towards a dense global GPS velocity field, AG Scientific Assembly, Budapest.

Lee, J., J. Spencer, and L. Owen (2001). Holocene slip rates along the Owens Valley fault, California; implications for the recent evolution of the Eastern California shear zone, Geology 29, 819-822.

Malservisi, R., T. H. Dixon, P. C. La Femina, and K. P. Furlong (2003). Holocene slip rate of the Wasatch fault zone, Utah, from geodetic data: earthquake cycle effects, Geophys. Res. Lett. 30, no. 13, 1673, doi 10.1029/2003GL0174078.

Mason, D. B. (1996). Earthquake magnitude potential of the Intermountain Seismic Belt, USA, from surface-parameter scaling of Late Quaternary faults, Bull. Seism. Soc. Am. 86, 1487-1506.

Masson, F., J. Chery, D. Hatzfeld, J. Martinod, P. Vernant, F. Tavakoli, and M. Ghafory-Ashtiani (2005). Seismic versus aseismic deformation in Iran inferred from earthquakes and geodetic data, Geophys. J. Int. 160, 217-226.

Mazzotti, S., H. Dragert, J. Henton, M. Schmidt, R. Hyndman, T. S. James, Y. Lu, and M. Craymer (2003). Current tectonics of northern Cascadia from a decade of GPS measurements, J. Geophys. Res. 108, 2554, doi 2510.1029/2003JB002653.

McCaplin, J. P., and S. P. Nishenko (1996). Holocene paleoseismicity, temporal clustering, and probabilities of future large $(M>7)$ earthquakes on the Wasatch fault zone, Utah, J. Geophys. Res. 101, 62336253.

McClusky, S. C., S. C. Bjornstad, B. H. Hager, R. W. King, B. J. Meade, M. M. Miller, F. C. Monastero, and B. J. Souter (2001). Present day kinematics of the Eastern California Shear Zone from a geodetically constrained block model, Geophys. Res. Lett. 28, 3369-3372.

Molnar, P. (1979). Earthquake recurrence intervals and plate tectonics, Bull. Seism. Soc. Am. 69, 115-133.

Nabelek, J. L., H. Eyidogan, and M. N. Tiksoz (1985). Source parameters of the Borah Peak, Idaho, earthquake of October 28, 1983 from bodywave inversion, EOS Trans. AGU 66, 308.

Oldow, J. S., C. L. V. Aiken, J. L. Hare, J. F. Ferguson, and R. F. Hardyman (2001). Active displacement transfer and differential block motion within the central Walker Lane, western Great Basin, Geology 29, $19-22$.

Pacheco, J., and J. Nábĕlek (1988). Source mechanisms of three moderate Californian earthquakes of July 1986, Bull. Seism. Soc. Am. 78, $1907-$ 1929.

Patton, H. J. (1985). P-wave fault plane solutions and the generation of surface wave by earthquakes in the Western United States, Geophys. Res. Lett. 112, 518-521.
Patton, H. J., and D. I. Doser (1988). Inversion of regional Pnl and surfacewave data for source parameters of the Borah Peak aftershock, Geophys. Res. Lett. 5, 459-462.

Rogers, A. M., S. C. Harmsen, E. J. Corbett, K. F. Priestly, and D. dePolo (1991). The seismicity of Nevada and some adjacent parts of the Great Basin, in Neotectonics of North America, D. B. Slemmons, E. R. Engdahl, M. D. Zoback, and D. D. Blackwell (Editors), Geological Society of America, Boulder, Colorado, Decade Map Volume 1, 153 184.

Savage, J. C., and L. M. Hastie (1966). Deformation associated with dipslip faulting, J. Geophys. Res. 71, 4897-4904.

Savage, J. C., and L. M. Hastie (1969). A dislocation model for the Fairview Peak, Nevada, earthquake, Bull. Seism. Soc. Am. 59, 1937-1948.

Savage, J. C., and M. Lisowski (1998). Viscoelastic coupling model of the San Andreas Fault along the big bend, southern California, J. Geophys. Res. 103, 7281-7292.

Savage, J. C., and R. W. Simpson (1997). Surface strain accumulation and the seismic moment tensor, Bull. Seism. Soc. Am. 87, 1345-1353.

Savage, J. C., W. J. Gan, W. H. Prescott, and J. L. Svarc (2004). Strain accumulation across the Coast Ranges at the latitude of San Francisco, J. Geophys. Res. 109, 3413, doi 3410.1029/2003JB002612.

Shen-Tu, B., W. E. Holt, and A. J. Haines (1998). Contemporary kinematics of the Western United States determined from earthquake moment tensors, very long baseline interferometry, and GPS observations, $J$. Geophys. Res. 103, 18,087-18,117.

Shen-Tu, B., W. E. Holt, and A. J. Haines (1999). Deformation kinematics in the western United States determined from Quaternary fault slip rates and geodetic data, J. Geophys. Res. 104, 28,927-28,955.

Shimazaki, K., and T. Nakata (1980). Time-predictable recurrence model for large earthquakes, Geophys. Res. Lett. 7, 279-282.

Sipkin, S. A. (1986). Interpretation of non-double-couple earthquake mechanisms derived from moment tensor inversion, J. Geophys. Res. 91, 531-547.

Slemmons, D. B. (1957). Geological effects of the Dixie Valley-Fairview Peak, Nevada, earthquakes of December 16, 1954, Bull. Seism. Soc. Am. 47, 353-375.

Slemmons, D. B., K. V. Steinbugge, D. Tocher, G. B. Oakshott, and V. P. Gianella (1959). Wonder, Nevada, Earthquake of 1903, Bull. Seism. Soc. Am., 49, 251-265.

Smith, S. W. (1976). Determination of maximum earthquake magnitude, Geophys. Res. Lett. 3, 351-354.

Smith, R. B., and W. J. Arabasz (1991). Seismicity of the intermountain seismic belt, in Neotectonics of North America, D. B. Slemmons, E. R. Engdahl, M. D. Zoback, and D. D. Blackwell (Editors), Geological Society of America, Boulder, Colorado, Decade Map Volume 1, 185228.

Smith, K. D., D. von Seggrenm, G. Blewitt, L. Preston, J. G Anderson, B. P. Wernicke, and J. L. Davis (2004). Evidence for deep magma injection beneath Lake Tahoe, Nevada-California, Science 305, 12771280.

Sonder, L. J., and C. H. Jones (1999). Western United States extension; how the west was widened, Ann. Rev. Earth Planet. Sci., 27, 417462.

Stein, R. S., and S. E. Barrientos (1985). Planar high-angle faulting in the Basin and Range: geodetic analysis of the 1983 Borah Peak, Idaho earthquake, J. Geophys. Res. 90, 11,355-11,366.

Stepp, J. C. (1972). Analysis of completeness of the earthquake sample in the Puget Sound area and its effect on statistical estimates of earthquake hazard, Int. Conf. Microzon. Proc. 2, 897-910.

Stewart, J. H. (1988). Tectonic of the Walker Lane Belt, Western Great Basin; Mesozoic and Cenozoic deformation in a zone of shear, in Metamorphism and Crustal Evolution of the Western United States, W. G. Ernst (Editor), Vol. 7, 683-713.

Svarc, J. L., J. C. Savage, W. H. Prescott, and M. H. Murray (2002a). Strain accumulation and rotation in western Oregon and southwestern Washington, J. Geophys. Res. 107, 2087, 7, doi 2010.1029/2001JB000625. 
Svarc, J. L., J. C. Savage, W. H. Prescott, and A. R. Ramelli (2002b). Strain accumulation and rotation in western Nevada, 1993-2000, J. Geophys. Res. 107, 2090, 13, doi 2010.1029/2001JB000579.

Thatcher, W. (1995). Microplate versus continuum descriptions of active tectonic deformation, J. Geophys. Res. 100, 3885-3894.

Thatcher, W. (2003). GPS constraints on the kinematics of continental deformation, Int. Geol. Rev. 45, 191-212.

Thatcher, W., G. R. Foulger, B. R. Julian, J. Svarc, E. Quilty, and G. W. Bawden (1999). Present-day deformation across the Basin and Range Province, Western United States, Science 283, 1714-1718.

Toppozada, T. R., C. R. Real, and D. L. Parke (1981). Preparation on isoseismal maps and summaries of reported effects for pre-1900 California earthquakes, annual technical report, U.S. Geol. Surv. OpenFile Rept. 81-11.

Tsai, Y-B., and K. Aki (1966). Source mechanism of the Truckee, California, earthquake of September 12, 1966, Bull. Seism. Soc. Am. 60, $1199-1208$.

Utsu, T. (2003). Relationships between magnitude scales, in International Handbook of Earthquake and Engineering Seismology W. H. K. Lee, H. Kanamori, P. C. Jennings, and C. Kisslinger (Editors), Vol. 81A, Academic Press, Amsterdam, 733-746.

Wallace, R. E. (1970). Earthquake recurrence intervals on the San Andreas fault, Bull. Geol. Soc. Am. 81, 2875-2890.

Wallace, R. E. (1984). Patterns and timing of Late Quaternary faulting in the Great Basin Province and relation to some regional tectonic features, J. Geophys. Res. 89, 5763-5769.

Wang, S. C., K. C. McNally, and R. J. Geller (1982). Seismic strain release along the Middle America Trench, Geophys. Res. Lett. 9, 182-185.

Ward, S. N. (1994). A multidisciplinary approach to seismic hazard in Southern California, Bull. Seism. Soc. Am. 84, 1293-1309.

Ward, S. N. (1998a). On the consistency of earthquake moment rates, geological fault data, and space geodetic strain: the United States, Geophys. J. Int. 134, 172-186.

Ward, S. N. (1998b). On the consistency of earthquake moment rates, geological fault data, and space geodetic strain: Europe, Geophys. J. Int. 135, 1011-1018.

Ward, S. N., and S. E. Barrientos (1986). An inversion for slip distribution and fault shape from geodetic observations of the 1983, Borah Peak, Idaho earthquake, J. Geophys. Res. 91, 4909-4919.

Wells, D. L., and K. J. Coppersmith (1994). New empirical relationships among magnitude, rupture length, rupture width, rupture area, and surface displacement, Bull. Seism. Soc. Am. 84, 974-1002.

Wernicke, B. (1992). Cenozoic extensional tectonics of the U.S. Cordillera in The Cordilleran Orogen: Conterminous U.S., The Geology of North America, Vol. G-3, P. W. Lipman, B. C. Burchfiel, and M. L. Zoback (Editors), Geological Society of America, Boulder, Colorado, 553581.

Wernicke, B. (1995). Low-angle normal faults and seismicity: a review, J. Geophys. Res. 100, 20,159-20,174.

Westaway, R., and R. B. Smith (1989), Source parameters of the Cache Valley (Logan), Utah earthquake of 30 August 1962, Bull. Seism. Soc. Am. 79, no. 5, 1410-1425.

Wong, I., W. Silva, S. Olig, P. Thomas, D. Wright, F. Ashland, N. Gregor, J. Peachman, M. Dober, G. Christenson, and R. Gerth (2001). Earthquake scenario and probabilistic ground shaking maps for the Salt Lake City, Utah, metropolitan area, Miscellaneous Publication 02-5, Utah Geological Survey, p 57.

Working Group on California Earthquake Probabilities (1995). Seismic hazards in southern California: probable earthquakes, 1994-2024, Bull. Seism. Soc. Am. 85, 379-439.

Zandt, G., S. C. Myers, and T. C. Wallace (1995). Crust and mantle structure across the Basin and Range-Colorado Plateau boundary at $37^{\circ} \mathrm{N}$ latitude and implications for Cenozoic extension mechanism, J. Geophys. Res. 100, 10,529-10,548.

\section{Appendix 1: Magnitudes of the Ten Largest Events}

$$
\text { Owens Valley 1872-3261030 }
$$

Moment magnitude estimates for this event were available from geology. Wells and Coppersmith (1994) give an estimate of $M_{\mathrm{W}} 7.61$, but we obtained $M_{\mathrm{W}} 7.58$ using their moment because equation (3) differs from their conversion from moment to magnitude. Beanland and Clark (1993) estimate an $M_{\mathrm{W}}$ value of 7.44-7.70. In addition, an $M_{\mathrm{W}}$ estimate of 7.74 was obtained from a moment estimate based on geology and felt area of the earthquake (Hanks et al., 1975). This value is quoted as $M_{\mathrm{W}} 7.80$ by Toppozada $e$ al . (1981) and documented as $M_{\mathrm{W}} 7.76$ from Hanks et al. (1975) in the U.S. historical catalog. Considering the geological observations to be more reliable than the felt area for estimating the earthquake size, we use the Beanland and Clark results to obtain the maximum and minimum estimate for the moment of this event, and use the Wells and Coppersmith parameters to obtain our best estimate.

\section{Pleasant Valley 1915-10 3653}

Doser (1988) gives a body-wave estimate of the earthquake size of $M_{\mathrm{W}}$ 6.82. However, Doser and Smith (1989) model this event as two subevents and obtain a best estimate of $M_{\mathrm{W}}$ 6.89. The lower bound on this best estimate of $M_{\mathrm{W}} 6.87$ gives us the minimum estimate of the size of this event. A number of geological estimates were also available. Doser (1988) and Doser and Smith (1989) quote a geological $M_{\mathrm{W}} 7.15$ from geological data using average displacements, a focal depth of $16 \mathrm{~km}$ and a dip of $60^{\circ}$. Wells and Coppersmith (1994) also obtain a geological estimate of $M_{\mathrm{W}} 7.15$, whereas our calculations using the Wells and Coppersmith data give an estimate of $M_{\mathrm{W}} 7.14$.

Because of the low magnitude of the body-wave estimate we retain the Wells and Coppersmith (1994) value of $M_{\mathrm{W}} 7.15$ for the final catalog, which is also the maximum estimate.

\section{Cedar Mountain 1932-12 21610}

Only body-wave and geological estimates were available for this event. Doser $(1986,1988)$ and Doser and Smith (1989) modeled this earthquake as two subevents. We choose the moment calculated by summing the individual moments of the two subevents as the best estimate of the body wave estimate of $M_{\mathrm{W}} 6.80$. The lower bound of this estimate of $M_{\mathrm{W}} 6.73$ gives us our minimum estimate.

Geological estimates were also available. Doser (1988) and Doser and Smith (1989) quote a geological estimate from Slemmons (1957) of $M_{\mathrm{W}}$ 7.09. Using data from Wells and Coppersmith (1994), we obtain a value of $M_{\mathrm{W}} 7.10$, which was the maximum estimate for this event. We prefer the geological estimates over the lower body-wave estimate 
obtained by Doser and Smith because the geological data are more representative of the extent of faulting than the shortwavelength body-wave data.

\section{Stillwater 1954-824551}

An average body-wave modeling estimate of $M_{\mathrm{W}} 6.50$ is given by Doser $(1986,1987)$ and Doser and Smith (1989), combining three subevents. Doser (1987) estimated $M_{\mathrm{W}} 6.55$ from Pnl. Barker and Doser (1988) invert for the seismic moment using teleseismic body waves, and $P n l$ waves separately, as well as both waveform types combined. Doser (1986, 1987) also gives estimates using body wave and $P n l$ waves, modeling the event as two subevents. A combined teleseismic-Pnl determination from inversion of both waveform types giving $M_{\mathrm{W}} 6.27$ (Barker and Doser, 1988) is preferred compared with separate inversions. Geological estimates were also given by Mason (1996), Doser (1987), and Doser and Smith (1989) and from the Wells and Coppersmith (1994) data of $M_{\mathrm{W}} 6.76, M_{\mathrm{W}} 6.41, M_{\mathrm{W}} 6.41$, and $M_{\mathrm{W}}$ 6.52 , respectively.

We prefer to use a value of $M_{\mathrm{W}} 6.76$, obtained using best estimates of geological parameters from Mason, whereas our maximum estimate of $M_{\mathrm{W}} 6.77$ comes from upper-bound estimates of these values. The minimum bound on the moment magnitude obtained from the literature was from Pnl modeling of $M_{\mathrm{W}} 6.16$ (Barker and Doser, 1988).

\section{Fairview Peak 1954-12 16117}

There are no fewer than 40 estimates of the magnitude for this earthquake. Two surface-wave estimates of $M_{\mathrm{W}} 7.35$ and $M_{\mathrm{W}} 7.12$, using different models of the focal mechanism, were given by Doser and Kanamori (1987), with two different focal mechanisms for both the Fairview Peak and Dixie Valley events. Doser and Smith (1989) quote the $M_{\mathrm{W}}$ 7.12 as their best surface-wave estimate. We also adopt this value as our preferred surface-wave magnitude estimate for this earthquake.

The largest estimated moment magnitude from the literature was from geological estimates obtained from Mason (1996) of $M_{\mathrm{W}}$ 7.36. Doser (1986) estimates $M_{\mathrm{W}} 6.91$ from body-wave modeling of two subevents, but the later study by Doser and Smith (1989) increases the minimum estimate to $M_{\mathrm{W}} 6.95$, which is what we use for the minimum estimate.

\section{Dixie Valley 1954-12 161111}

A surface-wave estimate of $M_{\mathrm{W}} 7.06$ was given by Doser and Smith (1989). Doser and Kanamori (1987) gave surface-wave estimates of $M_{\mathrm{W}} 7.15$ and $M_{\mathrm{W}} 6.92$ according to the two focal mechanisms that they employ for both the Fairview Peak and Dixie Valley events. In consistency with the Fairview Peak event, we choose to retain the best estimate of Doser and Smith (1989) $M_{\mathrm{W}}$ 7.06.
Body-wave estimates were given by Doser (1986) and Doser and Smith (1989). They both model the event as two subevents. Geological estimates of the moment magnitude were available from Caskey et al. (1996), Mason (1996) and Wells and Coppersmith (1994). Doser and Kanamori (1987) quoted the geological estimate from Slemmons (1957) and Savage and Hastie (1969). Doser and Smith (1989) also quoted an estimate of the geological moment magnitude from the literature. From body-wave modeling, the minimum estimate of $M_{\mathrm{W}} 6.53$ was estimated by Doser and Smith (1989), while the maximum of $M_{\mathrm{W}} 7.24$ comes from geological estimates (Caskey et al., 1996).

\section{Hebgen Lake 1959-8 18637}

Moment magnitude estimates were available from surface-wave and body-wave modeling as well as from geodetic and geological observations.

Doser (1985) modeled this event as two subevents, with the second subevent $5 \mathrm{sec}$ after the first. Doser and Smith (1989) provided a surface-wave estimate of $M_{\mathrm{W}} 7.32$ combining two subevents, whereas Doser and Kanamori (1987) calculated a surface-wave estimate of $M_{\mathrm{W}}$ 7.39. We retained the lowest surface-wave estimate of $M_{\mathrm{W}} 7.32$ from Doser and Smith (1989) as our best estimate from the literature.

Geological data from Savage and Hastie (1969) are used to derive an $M_{\mathrm{W}} 7.42$. This was the largest value of the moment magnitude obtained from the literature. A minimum value of $M_{\mathrm{W}} 7.01$ was obtained from Doser and Smith (1989) from geological estimates, which includes deformation for the whole sequence. We therefore prefer to use a minimum magnitude of $M_{\mathrm{W}} 7.25$ derived from body-wave modeling, which included two subevents (Doser, 1985; Doser and Smith, 1989).

\section{Borah Peak 1983-10 28146}

Harvard CMT estimate of $M_{\mathrm{W}} 6.93$ available for this event was retained as the final estimate of the earthquake size according to our selection criteria.

Moment tensor estimates of the moment magnitude were obtained from Ekstrom and Dziewonski (1985). Bodywave CMT estimates were also obtained from Nablek et al. (1985). Estimates for geodetic leveling data were obtained from Barrientos et al. (1985), Stein and Barrientos (1985), Ward and Barrientos (1986), and Doser and Smith (1989). Body-wave modeling estimates were provided from Barker and Doser (1988) and Doser and Smith (1989). Geological estimates were obtained from Wells and Coppersmith (1994), Doser and Smith (1989), and Mason (1996).

Geological parameters documented by Mason (1996) give a maximum estimate of $M_{\mathrm{W}} 7.25$. This was the largest estimate obtained from the literature. Both Ekstrom and Dziewonski (1985) and Nabelek et al. (1985) give an estimate of $M_{\mathrm{W}} 6.93$ from body-wave centroid moment tensor 
solutions and body-wave inversions, respectively. A minimum estimate of $M_{\mathrm{W}} 6.82$ is documented by Doser and Smith (1989) from body-wave modeling.

\section{Landers 1992-6 281157}

From the data provided by Wells and Coppersmith (1994), we calculate a minimum of $M_{\mathrm{W}} 7.19$. The maximum estimate is from Kanamori et al. (1992) who give an estimate of $M_{\mathrm{W}} 7.30$ from surface-wave inversion. However, a Harvard CMT moment magnitude estimate was available. As this estimate of $M_{\mathrm{W}} 7.29$ is favored above all others, this value of the earthquake size was retained in the final catalog.

\section{Hector Mine 1999-10 16946}

Harvard CMT estimate of $M_{\mathrm{W}} 7.12$ was available for this event and retained as the final estimate of the earthquake size according to our selection criteria. This was the maxi- mum estimate for this event a minimum estimate of $M_{\mathrm{W}} 7.10$ is given by the Berkeley (BK) and Council of the National Seismic System (CNSS) catalogs. The maximum estimate of $M_{\mathrm{W}} 7.14$ is from Ji et al. (2002).

Seismological Laboratory and Department of Geological Sciences University of Nevada

Reno, Nevada 89557

pancha@seismo.unr.edu

jga@unr.edu

(A.P., J.G.A.)

Nevada Bureau of Mines and Geology

Mail Stop 178

University of Nevada

Reno, Nevada 89557-0088

kreemer@unr.edu

(C.K.) 